\title{
The Legacy of the SIR-C/X-SAR radar system: 25 years on
}

Anthony Freeman ${ }^{1, *}$, Manfred Zink ${ }^{2}$, Ed Caro $^{1}$, Alberto Moreira ${ }^{2}$, Louise Veilleux ${ }^{1}$, Marian Werner $^{2}$

1. Jet Propulsion Laboratory, California Institute of Technology, Pasadena, CA 91109, USA 2. DLR, German Aerospace Center, Microwaves and Radar Institute, 82234 Oberpfaffenhofen, Germany

*Corresponding author: Tel: +1 (818) 3541887

e-mails: anthony.freeman@jpl.nasa.gov (A.Freeman); manfred.zink@dlr.de (M.Zink); edrcaro@aol.com (E.Caro); Alberto.Moreira@dlr.de (A.Moreira); adventconst@sbcglobal.net (L.Veilleux); marianwerner47@gmail.com (M.Werner)

\begin{abstract}
Twenty-five years ago, the two flights of the SIR-C/X-SAR Synthetic Aperture Radar (SAR) system on the Space Shuttle Endeavour blazed a trail toward the future with a series of radar system innovations - that nearly every spaceborne SAR flown since then has benefited from, and in some cases improved upon. Many of the SAR techniques adopted by SAR system designers worldwide as part of their toolkit, such as: ScanSAR, Spotlight mode, along-track interferometry, polarization diversity and polarimetry, polarimetric calibration, variable length and bandwidth pulses, and onboard processing, can trace their heritage back to this first-of-a-kind, civil-use SAR system. The electronic steering capability of SIR-C's phased array antenna, combined with the exquisite orbit track control provided by the Space Shuttle, paved the way for systematic mapping of the Earth's topography by the Shuttle Radar Topography Mission, and later by TanDEM-X. Some techniques, such as multi-frequency SAR, multi-frequency repeat-pass interferometry and onboard processing have yet to be fully exploited. The richness of the SIR-C/X-SAR data set has proved to be a treasure trove for opening up entirely new remote sensing techniques, such as Polarimetric SAR Interferometry (or PolInSAR), and GPS or now GNSS reflections (also known as Signals of Opportunity), which were both demonstrated from archive data, years after the 1994 flights. The ground-breaking legacy of SIR-C/X-SAR lives on in the many SAR systems collecting data in Earth orbit today, and in those planned for the future.
\end{abstract}

Keywords: SIR-C/X-SAR, Synthetic Aperture Radar, Polarimetry, Interferometry, MultiFrequency, Calibration, GPS Reflectometry 


\section{PREPRINT}

\section{Introduction}

\subsection{A brief history of the SIR-C/X-SAR system}

The most advanced civil-use spaceborne SAR system of its time, the Spaceborne Imaging RadarC/X-band Synthetic Aperture Radar (SIR-C/X-SAR) had its roots in a series of imaging radar missions that began with the NASA's Seasat synthetic aperture radar in 1978 (Evans et al, 2005). Seasat was a single frequency (L-band with wavelength of $24 \mathrm{~cm}$ ), single polarization, radar, with a fixed-look angle $\left(23^{\circ}\right)$. Next up in 1981 was the Shuttle Imaging Radar-A (SIR-A), which flew on the Space Shuttle Columbia, and was another L-band radar with a fixed look angle (Elachi et al, 1982). Mechanical steering for a multi-look angle capability was added and flown in 1984 as the SIR-B radar system (Cimino et al, 1986). In parallel, the German Aerospace Center (DLR, then called DARA) had also developed and flown an X-band (wavelength $3 \mathrm{~cm}$ ) SAR on the Space Shuttle Columbia in 1983 known as the Microwave Remote Sensing Experiment (MRSE) (Dieterle and Schlude, 1982).

From these beginnings, SIR-C/X-SAR was conceived as a joint venture between NASA, the German Space Agency (DLR), and the Italian Space Agency (ASI) (Jordan et al, 1995). SIR-C/XSAR provided increased capability over the prior Seasat, SIR-A, SIR-B and MRSE systems by acquiring images at three wavelengths: L-band, C-band (wavelength $\sim 6 \mathrm{~cm}$ ) and X-band. The Land $\mathrm{C}$-band radars could be tuned to select among several polarization options, and had the capability of full quad-polarized (or polarimetric) data acquisition. The X-band system, developed jointly by DLR and ASI, had VV polarization capability, transmitting and receiving vertically (V) polarized radar pulses. SIR-C/X-SAR also had a variable look angle, and could point towards look angles between 20 and 65 degrees off nadir by electronic steering at L- and C-band, and mechanically at X-band. SIR-C/X-SAR flew on the Space Shuttle Endeavour in April and October of 1994, providing radar science data representative of two seasons.

\subsection{Science Results}

Much has been written elsewhere about the science return from the SIR-C/X-SAR flights (Stofan et al, 1995; Öttl, 1997, Evans et al, 1997; Schmullius and Evans, 1997; Evans 2006) and that is not the primary focus of this paper. The science team was organized into sub-groups around several disciplines: Geology, Hydrology, Ecology, Oceanography, Electromagnetic Theory, Calibration and Rain/Interferometry. Data acquisitions and in situ calibration/validation efforts were focused at nineteen different 'supersites' geographically distributed across the globe. What the science team achieved across all of these disciplines, and at all these sites, was the validation of algorithms that generated geophysical data products from calibrated, multi-frequency, multi-polarization SAR backscatter data (Ranson et al, 1995; Dobson et al, 1995; Hess et al, 1995; Shi and Dozier, 1995; Dubois et al, 1995; Greeley and Blumberg, 1995; Mouginis-Mark, P. J., 1995; Beal and Monaldo, 1995; Moreira et al, 1995). A typical example is the inundation map from part of the Manaus, Brazil supersite shown in Figure 1. Other significant geophysical products include forest biomass estimates (Dobson et al, 1995), snow wetness (Shi and Dozier, 1995), soil moisture (Dubois et al, 1995) and surface wave fields in the Southern Ocean (Beal and Monaldo, 1995). The Calibration sub-group straddled the divide between science and engineering, producing fully calibrated data, along with calibration uncertainties (Zink and Bamler, 1995; Freeman et al, 1995; Sarabandi et al, 
1995; Ponte et al, 1997; Fang and Moore, 1997; Fujita et al, 1998), for the other sub-groups to then confidently apply and validate their geophysical estimation algorithms.

With over 5000 publications referencing the use of SIR-C/X-SAR data, the mission clearly has had a significant influence on active microwave remote sensing to understand and characterize the Earth system. Here we identify more of the most frequently cited results. Oceanographers found the data useful in studying surface features on the open ocean (Holt, 1998; Macklin and Stapleton, 1998; Monaldo and Beal, 1998; Melsheimer et al, 1998), including natural and man-made oil slicks (Masuko et al, 1995; Gade et al, 1998; Migliaccio et al, 2007). Snow hydrologists advanced their understanding of how microwaves can be used to probe the properties of snow packs (Shi and Dozier, 1997; Matzler et al, 1997; Shi and Dozier, 2000; Shi and Dozier, 2000a). Scientists investigating microwave remote sensing of precipitation found quite a few examples in SIR-C/XSAR data (Moore et al, 1997; Jameson et al, 1997). Land surface hydrologists mined rich veins of SIR-C/X-SAR data to investigate soil moisture variability (Wang et al, 1997; Macelloni et al, 1999; Narayanan and Hirsave, 2001) and wetlands (Pope et al, 1997; Pope et al, 2001; Alsdorf et al, 2001; Hess et al, 2003). Ecosystem scientists have applied SIR- C/X-SAR data to a diverse

\section{SIR-C/X-SAR \\ MANAUS, BRAZIL SUPERSITE INUNDATION MAP \\ APRIL 12, 1994}

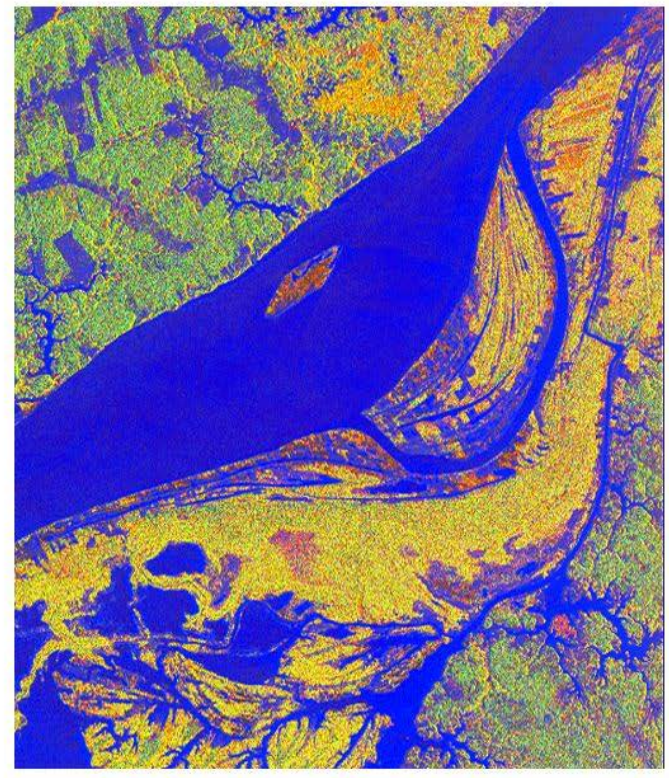

SIR-C IMAGE

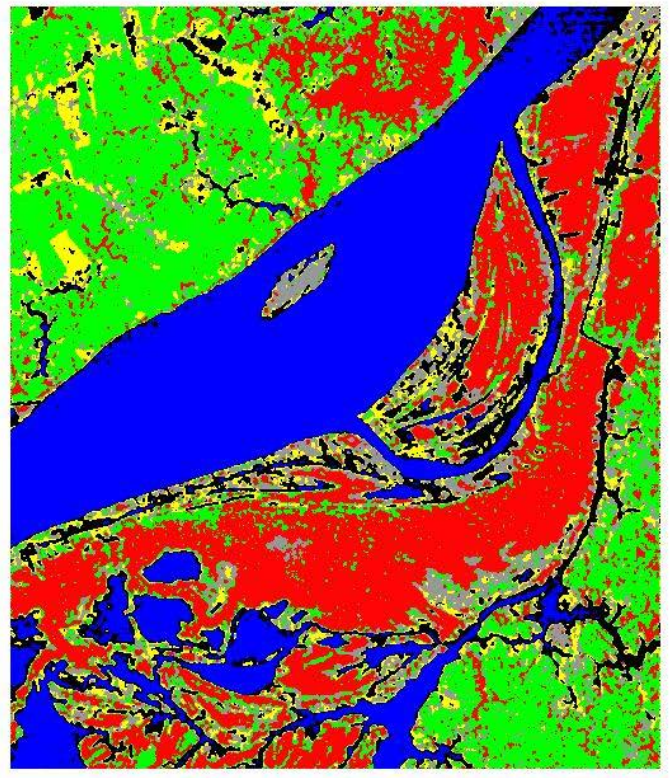

INUNDATION MAP

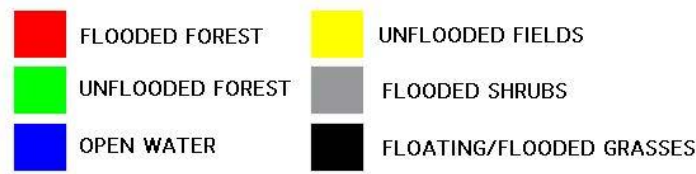

Figure 1: Inundation map (right) of part of the Manaus, Brazil supersite in the Central Amazon, generated from multi-polarization L-band SIR-C data (left) 


\section{PREPRINT}

range of vegetation biomes (Kasischke et al, 1997). Researchers have reported estimates of biomass and carbon storage in Northern and temperate forests (Souyris et al, 1995; Ranson and Sun, 1997; Harrell et al, 1997; Bergen et al, 1998; Ranson et al, 2001); deforestation and secondary growth in tropical forests (Saatchi et al, 1997; Foody et al, 1997; Rignot et al, 1997; Yanasse et al, 1997); and land use classification and monitoring in agricultural regions (Pultz et al, 1997; Soares et al, 1997; Ferrazzoli et al, 1997; Pierce et al, 1994; Pierce et al, 1998; Zribi et al, 1997; Nagai et al, 1997; Paloscia 2002). Volcanologists have found SIR-C/X-SAR data to be helpful in the study of both active and dormant volcanoes (Zebker et al, 1996; MacKay and Mouginis-Mark, 1997; Huadong et al, 1997; MacKay et al, 1998). Geologists found the data to be especially beneficial in revealing geologic features obscured by sand or vegetation cover (Kruse, 1996; Guo et al, 1996; Schaber et al, 1997; Weeks et al, 1997; Dabbagh et al, 1997; Stern and Abdelsalam, 1996; Abdelsalam and Stern, 1996; Kusky and Ramadan, 2002; Mchone et al, 2002). Cryosphere scientists have studied mid-latitude glaciers using SIR-C/X-SAR data (Forster et al, 1996; Albright et al, 1998; Floriciolu and Rott, 2001). New applications for the data, that emerged after the mission, include archaeology (Moore et al, 2006; Chen et al, 2015) and even prospecting for gold (Ramadan et al, 2001).

\subsection{System Description}

SIR-C/X-SAR was the first multi-frequency, multi-polarization SAR system flown in space (Stuhr et al, 1995). It's $12 \mathrm{~m}$ by $4 \mathrm{~m}$ antenna and radar electronics modules were mounted on an aluminum support structure which nearly filled the Shuttle cargo bay (Figure 2). The orbit altitude for both missions was roughly $225 \mathrm{~km}$. On-orbit the Shuttle was oriented so that the mechanical boresight of the L- and C-band antennas was about 40 degrees off nadir. Pointing over a wide range of look angles was achieved electronically via a phased array antenna at L- and C-band, and mechanically rotating the slotted waveguide antenna at X-Band. All three wavelengths were pointed towards the same look angle for each data acquisition. Left- and right-looking imaging configurations were achieved by re-orienting the Space Shuttle at intervals throughout each mission.

\begin{tabular}{|c|c|c|c|}
\hline Parameter & L-Band & C-Band & X-Band \\
\hline Wavelength & $0.235 \mathrm{~m}$ & $0.058 \mathrm{~m}$ & $0.031 \mathrm{~m}$ \\
\hline Spatial Resolution & \multicolumn{3}{|c|}{15 and $30 \mathrm{~m}$} \\
\hline Swath Width & \multicolumn{2}{|c|}{15 to $90 \mathrm{~km}$} & 15 to $60 \mathrm{~km}$ \\
\hline Look angles & \multicolumn{3}{|c|}{20 to 55 degrees } \\
\hline Peak RF Transmit power & $4400 \mathrm{~W}$ & $1200 \mathrm{~W}$ & $1400 \mathrm{~W}$ \\
\hline Transmit Pulse length & \multicolumn{2}{|c|}{33.2 and $8.5 \mu \mathrm{s}$} & $40 \mu \mathrm{s}$ \\
\hline Bandwidth & \multicolumn{3}{|c|}{10,20 and $40^{*} \mathrm{MHz}$} \\
\hline Quantization & 8 or 4 bit & BFPQ; offset video & 4 or 6 bits; I and Q \\
\hline Single-Pol Modes & & , or VV & VV \\
\hline Dual-Pol Modes & $(\mathrm{HH}, \mathrm{HV}$ & $\mathrm{VV})$ and $(\mathrm{HH}, \mathrm{VV})$ & - \\
\hline Quad-Pol Modes & & VH and VV & - \\
\hline StripMap mode & & Yes & Yes \\
\hline ScanSAR mode & & Yes & \\
\hline Spotlight Mode* & & Yes & \\
\hline Along-Track Interferometry* & & Yes & \\
\hline Real-time OBP* & & d HH only & \\
\hline
\end{tabular}

Table 1: SIR-C/X-SAR radar system parameters, illustrating the wide variety of options available for any given data acquisition. Experimental modes are indicated by an asterisk. 


\section{PREPRINT}

As the Shuttle approached each supersite, the antenna was pointed so that the radar's footprint on the ground would cover it. The challenge then for the radar systems engineering team was to predetermine the appropriate mode for the radar system, and set up the commands to execute it. Officially, the system had 23 modes to choose from (Stofan et al, 1995), but as can be seen from Table 1, there were in fact a very broad range of options available. Fortunately, some were categorized as 'experimental' modes, and were not routinely offered to the science team subgroups as options. A limiting factor in SIR-C/X-SAR operations were the onboard data recorders, which could accommodate $180 \mathrm{Mbps}$ for the L- and C-band receivers, and $45 \mathrm{Mbps}$ for the X-band. Taking this into account, the widest swath widths were obtained when operating with just one polarization at each wavelength; then as additional polarizations were added the swaths became narrower.

Data was acquired more or less continuously during each 10-day mission, with occasional breaks so the astronaut crew could reload the onboard tape recorders, where all of the data was stored for later processing on the ground. A limited amount of data was relayed to the ground in real-time through TDRS, which allowed for some very fast turnaround SAR data processing and calibration runs (Freeman et al, 1994), and for the science teams to test out some of their algorithms during the mission.
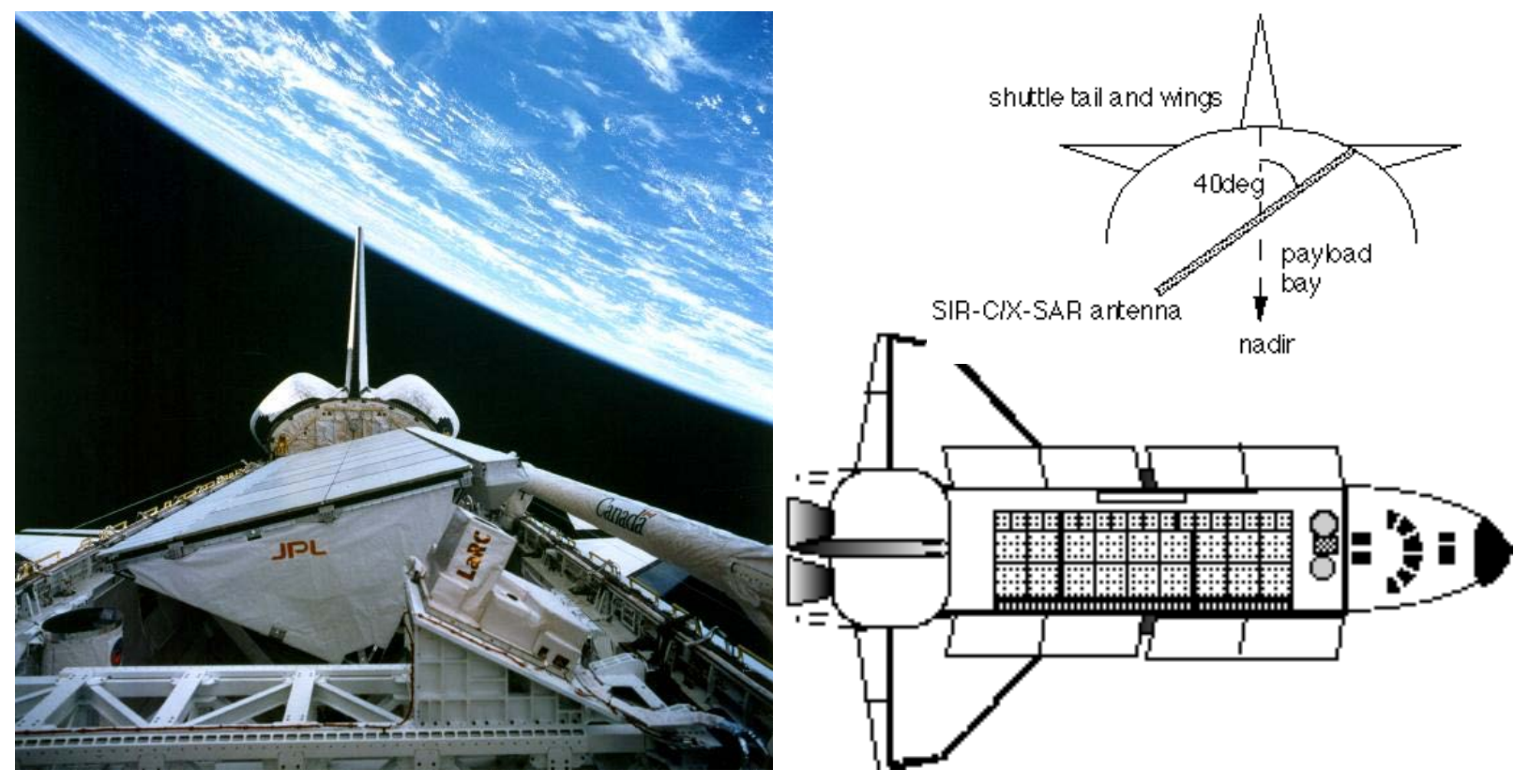

Figure 2: The SIR-C/X-SAR system with its antennas pointed Earthwards in the cargo bay of the Space Shuttle Endeavour. On-orbit photo (left); cartoon sketches showing the configuration of the radar in the Shuttle cargo bay (right). 


\section{PREPRINT}

\section{Radar System Innovations}

The 1994 SIR-C/X-SAR missions generated a series of firsts for a civil-use, spaceborne SAR system. What follows is a brief discussion of each of these innovations and their significance.

\subsection{First electronically steerable, phased array SAR}

Really two phased array systems (the L- and C-band antennas were independent of each other) the SIR-C antennas had a distributed feed network with Transmit/Receive (T/R) modules mounted on the backplane (Jordan et al, 1995). Separate feed networks and T/R modules fed the H and V channels which were connected to microstrip patch radiating elements on the front face of each antenna. This delivered the capability to transmit and receive both polarizations simultaneously. Phase shifters embedded in each T/R module could be programmed to electronically point the antenna pattern $+/-23$ degrees in elevation, $+/-2$ degrees in azimuth. Antenna feeds were divided into two branches (fore and aft) which were usually combined, but could also be fed separately into the receiver subsystems, enabling an experimental along-track interferometry (ATI) mode.

The innovation of using a SAR with a phased array enabled near-instantaneous antenna pointing changes, guaranteeing coverage of all the science supersites on nearly every overpass; and enabled new modes of operation, such as ScanSAR, Spotlight and ATI. An additional benefit of using distributed T/R modules, with low power amplifiers, instead of a single high-power amplifier (e.g. a Travelling Wave Tube Amplifier or TWTA), is that it reduces the losses in the feed network which would be considerable in the case of such a large antenna (Jordan et al, 1995). The flexibility and resiliency that a phased array antenna affords have been incorporated into the design of many civil-use SAR systems that have flown since 1994 (Table 2).

\subsection{First multi-frequency SAR}

Combining all three wavelengths into one spaceborne SAR system had not been done before (or since). It allowed scientists to compare simultaneously acquired radar backscatter characteristics across frequencies using targets representative of the entire Earth, and select the appropriate frequency for a given set of science drivers for future missions, such as the Shuttle Radar Topography Mission (SRTM) (Farr et al, 2007) and TanDEM-X (Krieger et al, 2007; Rizzoli et al, 2017). For example, if the goal is to study long-term surface deformation L-band is preferred, since it leads to less decorrelation in vegetated areas (Rosen et al, 1996); whereas if the goal is to map surface topography, shorter wavelengths were seen to perform better (C- and $\mathrm{X}$-band). Figure 3 illustrates how each of the three bands can provide different information about the area under investigation.

\subsection{First civil-use X-band SAR}

MRSE was supposed to precede X-SAR as the first civil-use X-band SAR, but because of an onorbit malfunction, that honor goes instead to X-SAR. The results from the 1994 missions showed that X-band SAR had value in mapping geophysical characteristics of the Earth's surface, beyond reconnaissance of targets of geopolitical interest (Gunter's Space Page, 1964). This realization led to a slew of X-band spaceborne SARs for civil-use, as can be seen in Tables 2 and 3. 


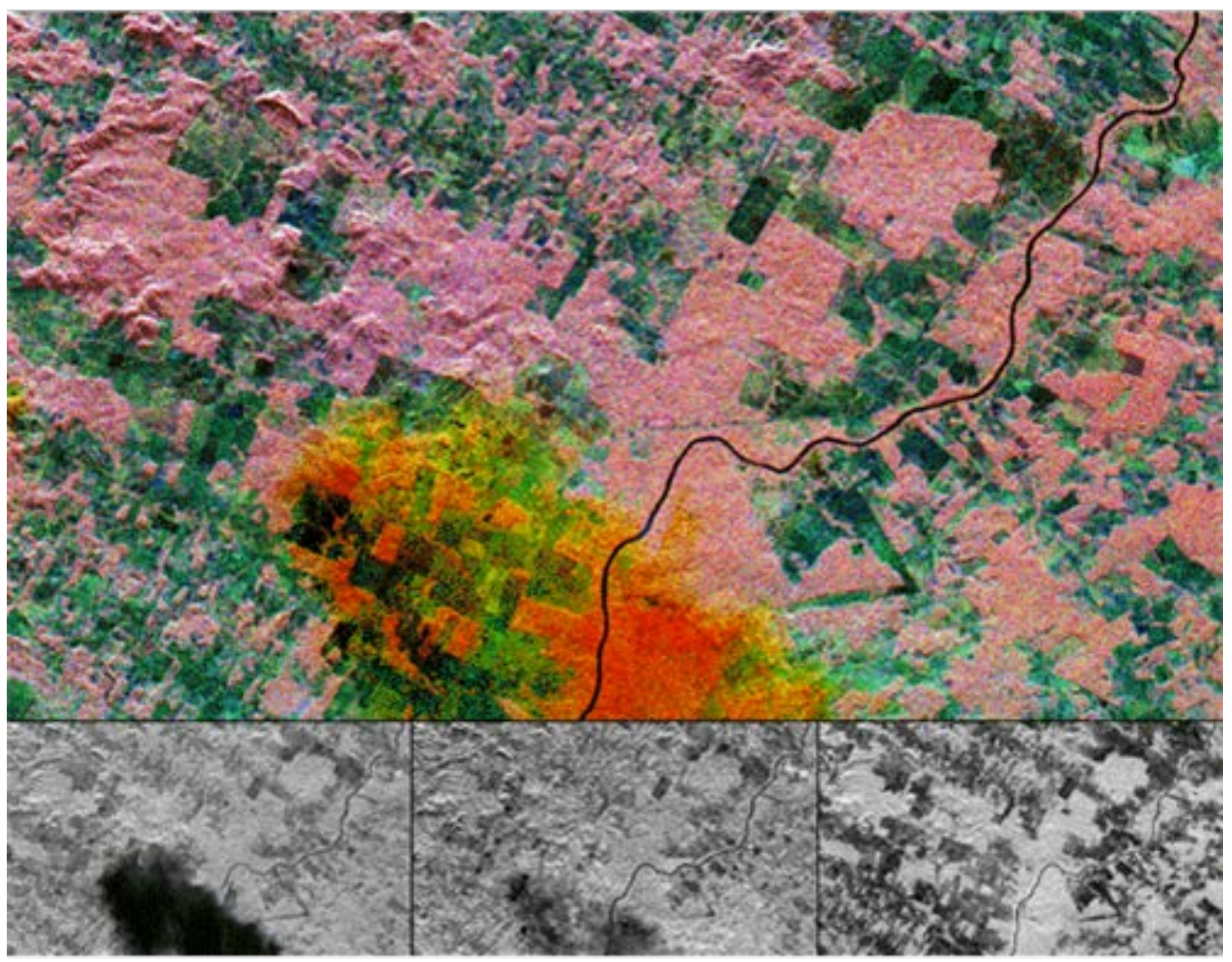

Figure 3: Three-frequency SIR-C/X-SAR overlay of a rain event observed over an area of tropical rainforest in Rondonia, western Brazil. The image frames at the bottom of the frame are, from left to right, X-band VV-pol, C-band HV-pol, and L-band HV-pol. In the color composite image these same frames are color-coded blue, green and red.

\subsection{First SAR with polarization diversity}

The Seasat, SIR-A, SIR-B and MRSE SAR systems (Evans et al, 2005; Elachi et al, 1982; Cimino et al, 1986; Dieterle and Schlude, 1982) were all single-polarization systems, as were the European ERS-1 (Attema et al, 2000) and Japanese JERS-1 (Nomoko et al, 1991) already on orbit in 1994, and the Canadian Radarsat-1 which launched in 1995 (Ahmed et al, 1993). SIR-C could transmit horizontally polarized $(\mathrm{H})$ or vertically polarized $(\mathrm{V})$ radar pulses, and receive either $\mathrm{H}-$ or $\mathrm{V}$ polarized echoes. The convention used is that $\mathrm{HV}$ means $\mathrm{H}$-polarization transmit, $\mathrm{V}$-polarization receive. SIR-C could therefore acquire multiple combination of (HH, HV, $\mathrm{VH}$ and VV) polarizations at both L-band and C-band (Table 1). Results from the 1994 missions demonstrated the value of multi-polarization measurements in science investigations, and nearly every civil-use SAR launched since has incorporated this capability, either as dual- or quad-polarized imaging systems (Table 2). 


\section{PREPRINT}

\subsection{First fully polarimetric SAR}

When all four canonical elements of the Scattering Matrix (HH, HV, VH and VV radar echoes) are measured coherently and simultaneously, one can separate out the different physical scattering mechanisms contributing to the observed radar backscatter (van Zyl, 1989; Freeman and Durden, 1998). Mathematical decompositions of the scattering matrix into separate, often orthogonal components (Figure 4), provide a powerful tool for discriminating between and understanding the nature of surface features (Cloude and Pottier, 1996).

The field of Radar Polarimetry was given a significant boost by the SIR-C/X-SAR mission. For the first time, researchers had access to fully calibrated, polarimetric SAR data sets that covered large areas at similar look angles (Figure 4). Previous airborne data had variable incidence angles across each image, which changes the scattering characteristics significantly (Freeman et al, 1992).

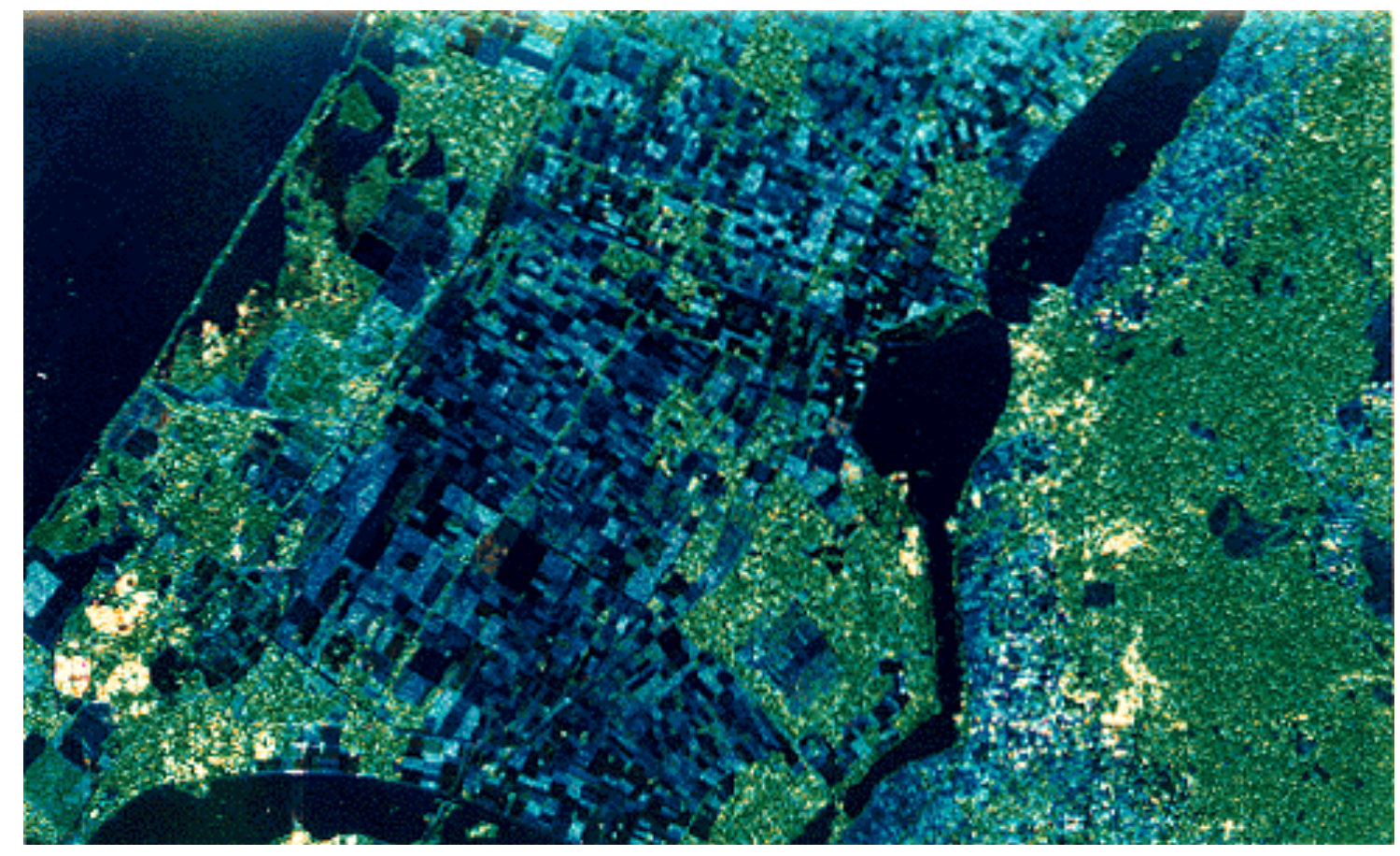

Figure 4: The Freeman-Durden decomposition applied to L-band SIR-C polarimetric SAR data over the Flevoland supersite, in the Netherlands. Blue = surface scattering; Red = doublebounce; and Green = Volume scattering. Areas that show up yellow have strong double-bounce scattering, mixed with volume scatter.

\subsection{First ScanSAR}

Can wide swath coverage be obtained from a SAR system so that larger areas can be accessed from orbit, and temporal revisit frequency can be increased? Using the electronic steering capability of SIR-C's phased array antennas to point the antenna footprint at multiple sub-swaths in elevation during a single pass over a target area, it was shown for the first time that this was indeed possible (Chang et al, 1995), with the trade-off being reduced spatial resolution in the along-track or azimuth dimension (Figure 5). This demonstration of obtaining wide swath 
coverage by rapidly switching between sub-swaths in elevation was an enabling capability for the SRTM mission (Farr et al, 2007), and has been adopted since in many subsequent spaceborne SAR systems (Table 2).

Since SIR-C/X-SAR, SAR designers have found ways to improve on the ScanSAR technique. Due to the so-called scalloping effect (Bamler, 1995) ScanSAR images are impacted by systematic SNR variations in the azimuth direction. To overcome this problem the Terrain Observation by Progressive Scans (TOPS) mode combines the scanning in elevation with a backward to forward steering (opposite to spotlight mode) of the beam in flight direction (de Zan and Monti Guarneri, 2006).

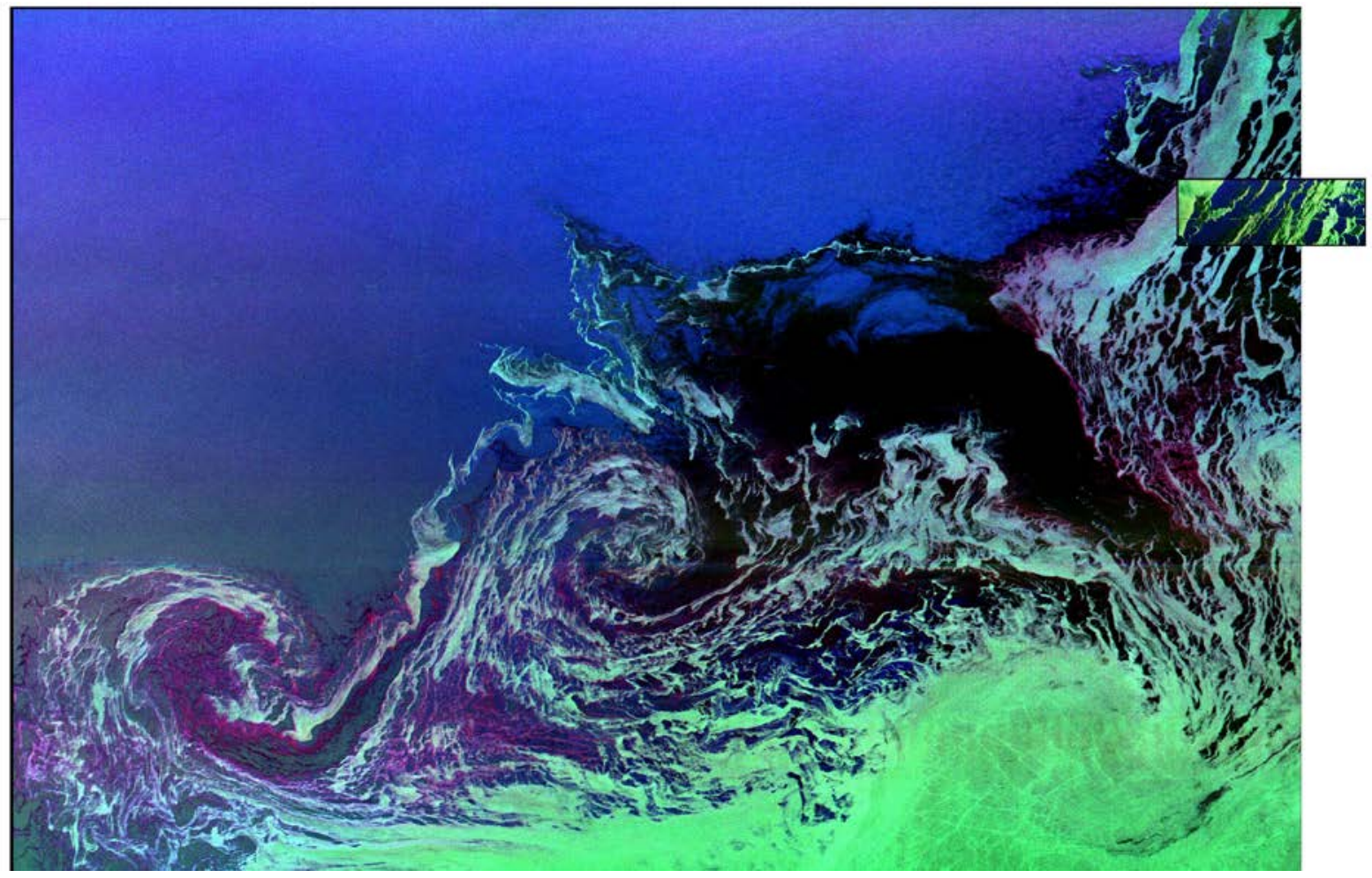

Figure 5: First SIR-C/X-SAR ScanSAR image of ocean and sea ice features in the Weddell Sea near Antarctica. The image is multi-frequency (C- and L-band) and multi-polarization (VH and VV), with dimensions $240 \mathrm{~km}$ x $350 \mathrm{~km}$. The small inset image at top right is a narrower-swath SIR-C/X-SAR image acquired the following day.

\subsection{First Spotlight SAR}

By electronically steering the phased array antenna in azimuth, so the footprint remains pointed towards a particular target area, the resulting data can be processed to obtain higher azimuth resolution than the classical half the antenna length (L/2) limit. This was demonstrated via a Spotlight mode SIR-C data acquisition over Sydney, Australia on the second mission (Figure 6).

This experimental mode for the SIR-C/X-SAR mission has since been incorporated into the design of more than a few SAR systems, for use when high spatial resolution is really needed. For 


\section{PREPRINT}

example, the staring spotlight mode on TerraSAR-X fully exploits the steering capabilities and can provides azimuth resolutions down to $20 \mathrm{~cm}$ (Mittermayer et al, 2014).

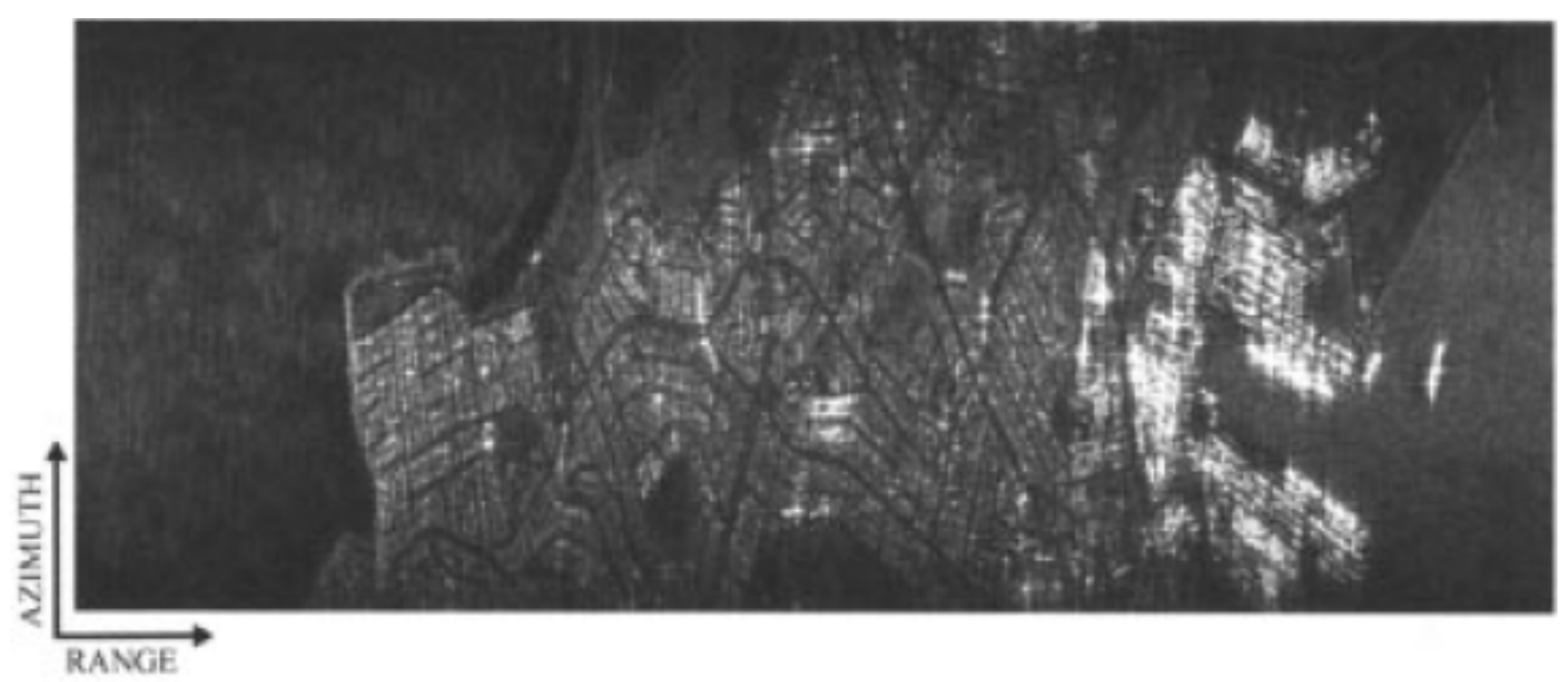

Figure 6: First C-Band VV polarization Spotlight SAR image from SIR-C/X-SAR data acquired over Sydney, Australia (Lanari et al, 2001). Image dimensions are $1.7 \mathrm{~km}$ x $4.5 \mathrm{~km}$. Spatial resolution is $\sim 1 \mathrm{~m}$ in azimuth, $\sim 8 \mathrm{~m}$ in range.

\subsection{First onboard 2-D SAR and real-time processing}

The Johns Hopkins University Applied Physics Laboratory (JHU/APL) added an electronics box to the SIR-C radar electronics that tapped off the C-band $\mathrm{HH}$ receive chain and processed the data acquired in real-time, turning the resulting focused SAR images into wave spectra for downlink through NASA's Tracking and Data Relay Satellite (TDRS) relay (Beal and Monaldo, 1995; Beal et al, 1991). This introduction of Onboard processing (OBP) was well ahead of its time, and to our knowledge this innovation has been adopted by no civil-use SAR system designed and built since (Table 2).

A ground-based real-time processor was developed for the X-SAR system, which was integrated in the mission control facilities in the Space Center Houston. Depending on the availability of TDRS relay, the X-SAR raw data was downlinked and processed with an azimuth resolution of 16 $\mathrm{m}$ to $60 \mathrm{~m}$ using a simplified SPECAN (Spectral Analysis) algorithm. The real-time processing allowed a quick cross-check of the data quality, optimization of the radar instrument parameters and provided a fast access of the data by the mission science. The images were also displayed on NASA television in real-time during the mission.

\subsection{First along-track interferometer}

On both flights of SIR-C/X-SAR, the ATI mode was exercised over the Gulf Stream supersite (Mango et al, 1995), with a phase center offset of half the physical antenna length -6 meters. In situ surface current measurements were collected to compare with ocean surface motion estimates from the ATI data. Because of the short baseline between phase centers, the sensitivity of these ATI measurements of opportunity was somewhat limited, but the general feasibility of current 
measurements from satellites using SAR interferometry was demonstrated (Romeiser et al, 2002). The split antenna concept has been adopted on TerraSAR-X and TanDEM-X to provide ATI measurements and an experimental fully polarimetric mode (Bueso-Bello et al, 2017).

\subsection{First rapid-turn-around Cal/Val}

Data from the Seasat, SIR-A, and SIR-B missions was not routinely calibrated. Quick-look images were available for ERS-1 and JERS-1, but users often had to wait many months to get their hands on fully calibrated data products. During both SIR-C/X-SAR missions, rapid response teams were engaged in processing and turning out the first calibrated data products within hours of their acquisition (Zink and Bamler, 1995; Freeman et al, 1995). A multitude of calibration devices including corner reflectors, transponders, tone generators and signal receivers were deployed at

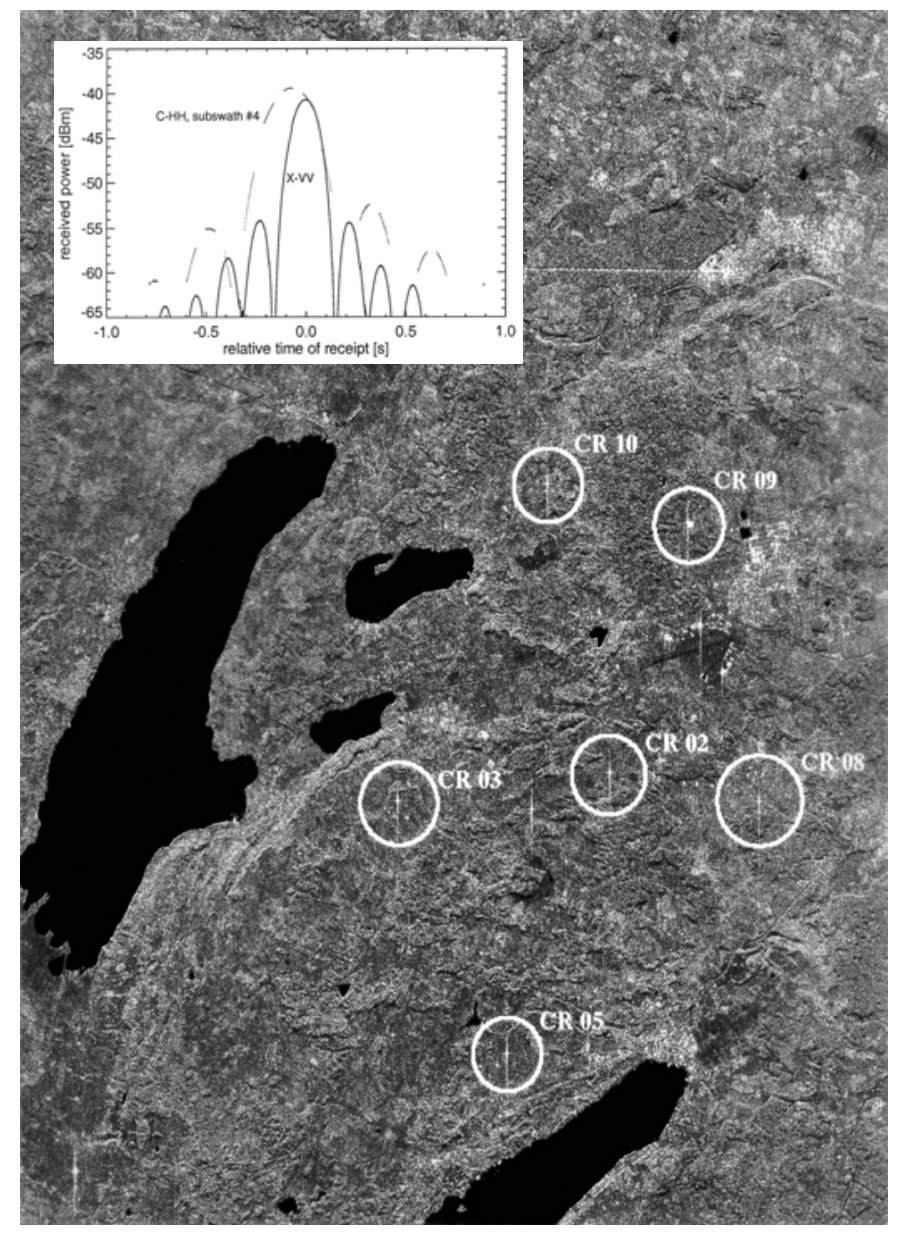

Figure 7: X-SAR image acquired over the calibration supersite around DLR Oberpfaffenhofen, Germany showing the point target response of six $3 \mathrm{~m}$ trihedral corner reflectors. The insert shows azimuth cuts through the $\mathrm{C}$-band and $\mathrm{X}$-band antenna patterns measured by ground receivers (gaps in the C-band data are due to the ScanSAR operation). The observed slight time offset between the peaks, corresponding to a squint of about $0.1 \mathrm{deg}$, was not a problem during the SIR-C/X-SAR mission, but later became an issue for SRTM that was addressed by electronic steering of the second antenna mounted on the tip of the boom (Geudtner et al, 2002). 
several of the supersites distributed around the world (see example in Figure 7). The objective was to get calibrated data acquired over the supersites into the hands of science investigators as quickly as possible, so they could validate their algorithms and generate geophysical parameters (Stofan et al, 1995). This practice became more common following SIR-C/X-SAR (Table 2).

\subsection{First topographic mapping using repeat-pass interferometry (RPI) at optimum angles}

Repeat-pass interferometry was demonstrated using Seasat, ERS-1 and JERS-1 data prior to SIR$\mathrm{C} / \mathrm{X}-\mathrm{SAR}$, but none of these systems were set up for optimum topographic mapping. In the case of Seasat and ERS-1, with a fixed look angle of 23 degrees from nadir, the resulting images in areas of significant topographic relief had too much layover and shadow. JERS-1 had a more favorable look angle of 35 degrees, but the system signal-to-noise and orbit track repeatability and knowledge were unsuitable. On the last three days of the second SIR-C/X-SAR flight, the Shuttle crew were able to adjust and lock down their orbit to repeat ground tracks to within about 50 meters. This enabled long swaths of RPI data (Figure 8) at all three wavelengths, with a baseline separation optimized for topographic mapping to be acquired and processed (Lanari et al, 1996; Rosen et al, 2000).
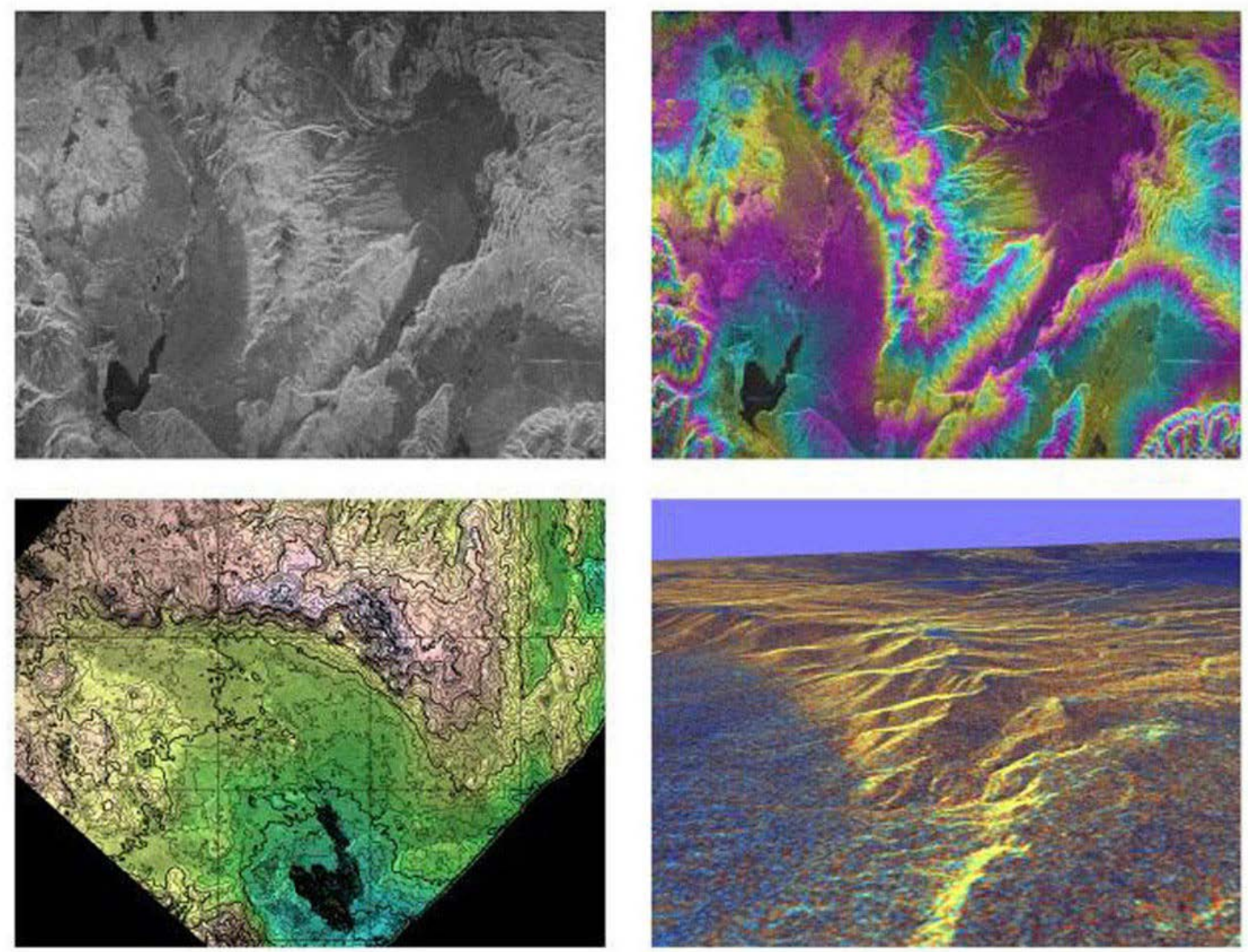

Figure 8: RPI for topographic mapping example from the second mission, acquired over Long Valley, CA. Radar backscatter image (top left): radar interferogram (top right); DEM derived from the interferogram (bottom left); and perspective view of the DEM (bottom right). 
This paved the way for SRTM single-pass interferometry (SPI) data processing in 2000, to produce a near-global Digital Elevation Model (DEM) with $30 \mathrm{~m}$ postings, and $10 \mathrm{~m}$ height accuracy (Farr and Kobrick, 2000; Farr et al, 2007). X-SAR RPI and the experience DLR gained with X-band topographic mapping on SRTM led to an even better global DEM (12 m postings, $2 \mathrm{~m}$ height accuracy) produced by the TanDEM-X mission starting in 2010 (Krieger et al, 2007; Zink et al, 2014); again using SPI, but from two separate platforms in bistatic radar operation, flying in formation with adjustable baseline geometry.

\subsection{First multi-frequency RPI for surface deformation}

The SIR-C/X-SAR missions enabled RPI studies of surface deformation over two timescales: the six months between the two Shuttle flights, and the day-to-day revisit during the orbit track lockdown period at the end of the second mission. Comparing across frequencies, the results indicated that longer wavelengths suffered less from decorrelation between observations in vegetated areas (Rosen et al, 1996; Lee et al, 2000). Multi-frequency, multi-pass coherence maps in non-vegetated areas, for example Figure 9, were seen to provide better maps for geologic interpretation than SAR images alone (Coltelli et al, 1996).

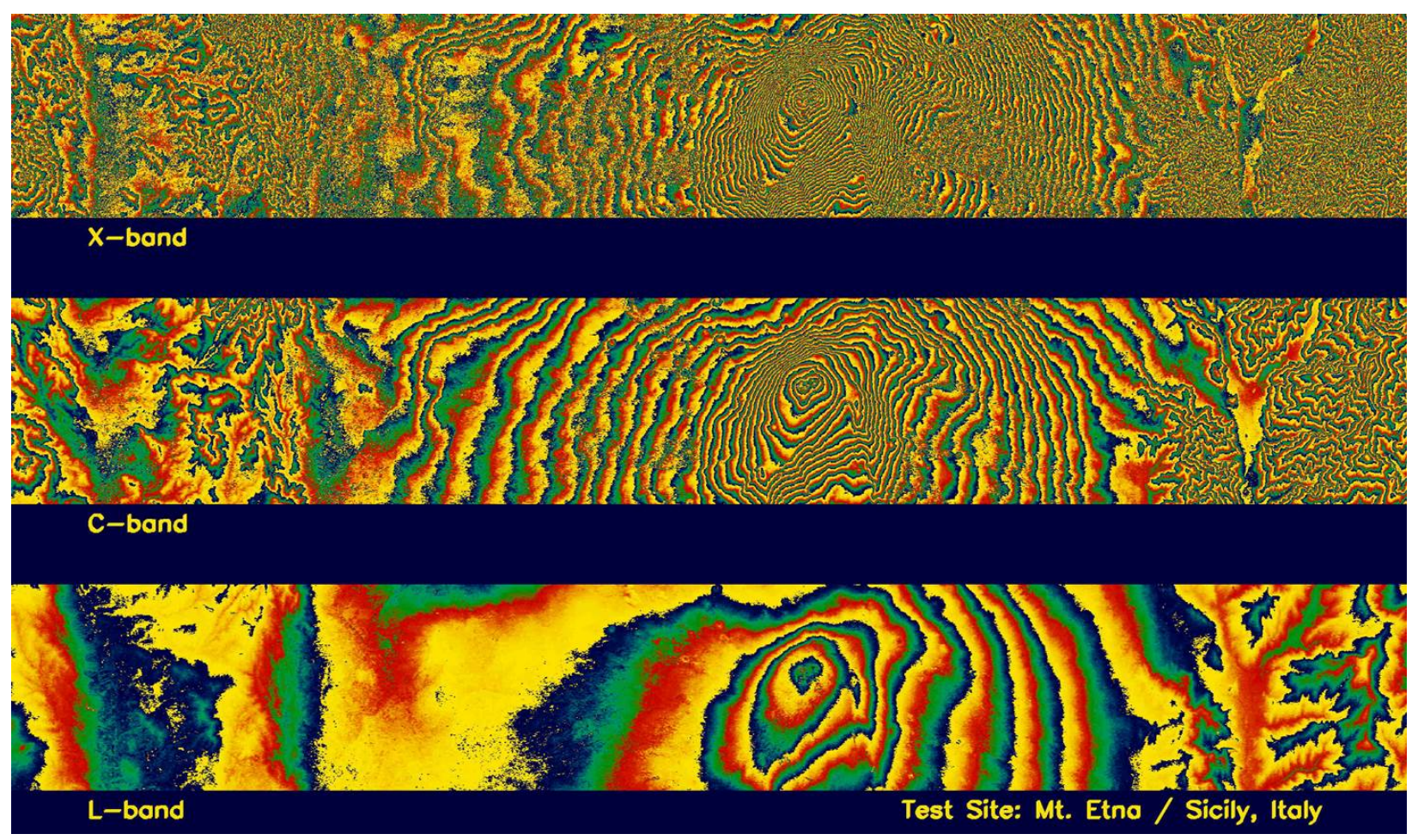

Figure 9: Multi-frequency interferograms from SIR-C/X-SAR acquired over Mt. Etna, Italy, showing the differences in coherence between X-band (top), C-band (middle), and L-band (bottom) (Moreira et al, 1995). 


\section{PREPRINT}

\subsection{First demonstration of several system performance enhancements:}

The first generation of spaceborne SARs suffered from severe dynamic range problems. JERS-1 for example had 3-bit Analog-to-Digital convertors (ADCs) with a variable gain amplifier in front, to try to maintain the power level of the received echoes in the 'sweet spot' for the ADCs. Radarsat1 had 4-bit ADCs, and ERS-1 had 5-bit ADCs. The dynamic range of a perfectly engineered ADC is roughly the number of bits multiplied by 6 in $\mathrm{dB}$. This can be lower than the dynamic range of the observed backscatter within the received radar echoes, so ERS-1, JERS-1 and Radarsat-1 all suffered to a degree from ADC saturation effects which led to distortion in the radar measurements (Meadows, 1994). In addition, all three generated In-Phase and Quadrature (I/Q) channels which were digitized separately. Since the I and Q channels were never truly orthogonal, this introduced an extra complication into the calibration of SAR data from these systems.

The SIR-C receiver system design incorporated 8-bit ADCs, with $\sim 48 \mathrm{~dB}$ dynamic range, and the transmitter had a variable pulse width to adjust the expected SNR for observations over different terrain types (e.g. open ocean, forested areas, grassland and farmland, desert, etc.). The radar also had variable bandwidth settings (Table 1) and used an offset video receiver (one channel instead of the two needed for I/Q).

Due to the low orbital altitude $(\sim 225 \mathrm{~km})$ of the Space Shuttle and the high peak power available, the thermal noise-equivalent sigma-zero was generally expected to be very low for all three radars (-40 dB at L-band; $-35 \mathrm{~dB}$ at C-band; and $-22 \mathrm{~dB}$ at X-band according to Jordan et al, 1995). Most SIR-C data-takes used an $(8,4)$ Block Floating Point (BFPQ) quantization scheme, and the roundoff error introduced by the BFPQ step tended to define the image noise floor at about $18 \mathrm{~dB}$ below the average backscatter level in the scene. In at least one case, a very low backscatter scene was imaged using 8-bit quantization and the noise floor was estimated at -50 dB for L-Band and -35 dB for C-Band (Freeman et al, 1995). X-SAR data too had much lower noise floors than advertised, ranging from -27 to $-44 \mathrm{~dB}$ as seen on-orbit (Zink et al, 1995).

Because of all these enhancements, the radiometric quality of SIR-C/X-SAR data was very high and as faster 8-bit ADCs, BFPQs, digital pulse generators, and offset video receiver designs have become more prevalent, later generation SAR systems have risen to similar standards of quality (Table 2).

\subsection{First acquisition of PolInSAR data}

Very few data sets were acquired in full polarimetric mode during the 3-day orbit lockdown on the second SIR-C/X-SAR mission, but serendipitously it turned out that would be enough to demonstrate the validity of an entirely new technique in radar remote sensing: Polarimetric SAR Interferometry, or PolinSAR (Cloude and Papathanassiou, 1998). PolInSAR is a very powerful tool for estimating forest height, and to first order, the structure of vegetation canopies (Cloude et al, 2003; Li et al, 2003), as seen in Figure 10. It is a foundational technique for the European Space Agency (ESA)'s future BIOMASS mission (Le Toan et al, 2011), NASA and ISRO's future NISAR mission (JPL, 2019), and for DLR's planned Tandem-L mission (Krieger et al, 2010; Moreira et al, 2015). 

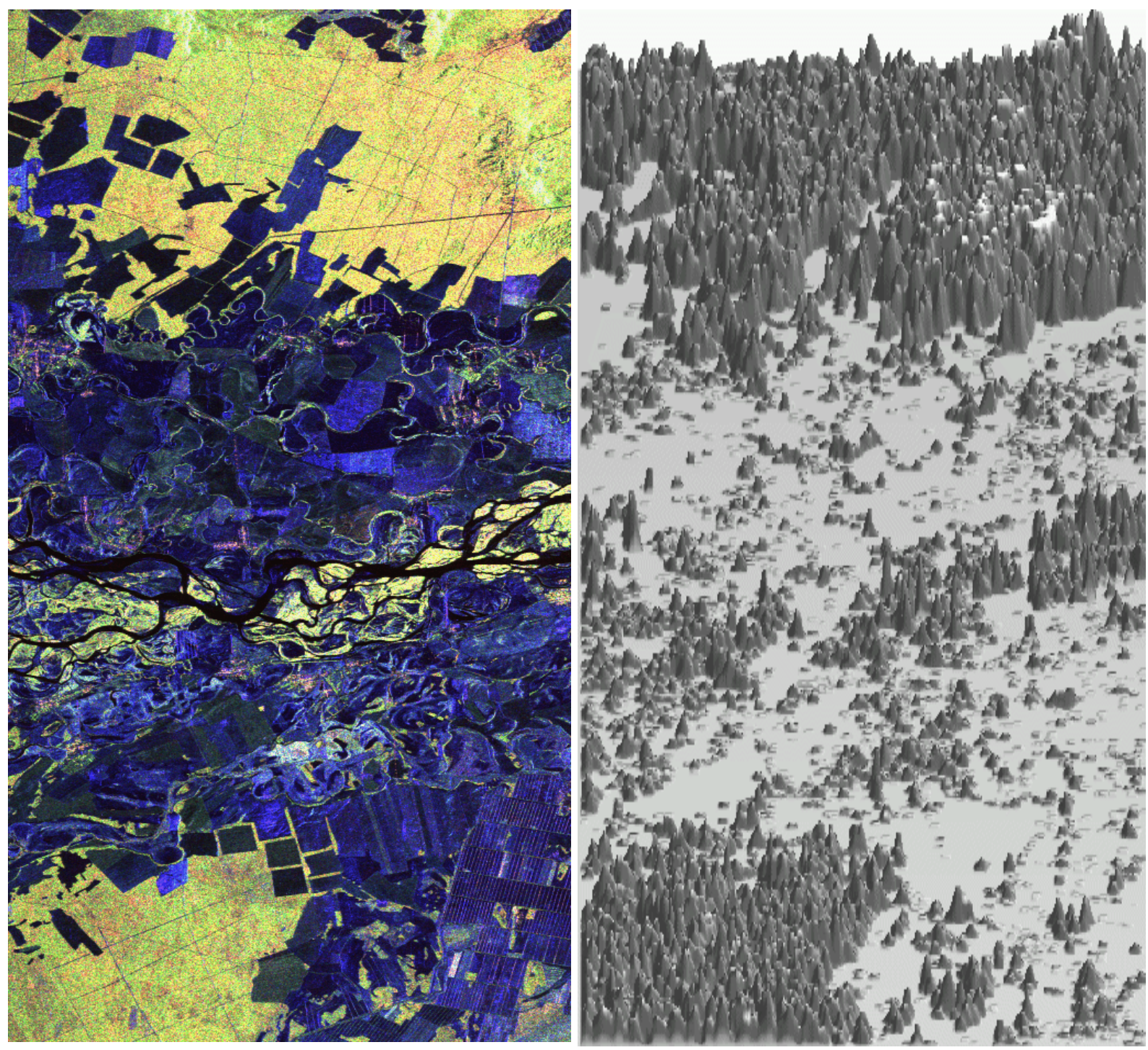

Figure 10: Perspective view (right) of a boreal forest in Siberia generated from PolInSAR data, and corresponding multi-polarization L-band SAR image (left) from SIR-C/X-SAR, showing the potential of this new technique for estimating the forest height. Image courtesy Shane Cloude/Kostas Papathanassiou (Cloude and Papathanassiou, 1998).

\subsection{First GPS reflection measurement from space}

Another, somewhat unexpected, result from SIR-C/X-SAR was the first measurement of L-band Global Positioning System (GPS) signals reflected from the ocean surface (Lowe et al, 2002). A re-analysis of archived SIR-C L-band data discovered data-takes that contained a strong, bistatic specular GPS reflection from a relatively smooth ocean. This paved the way for NASA's Cyclone Global Navigation System Satellites (CyGNSS) mission, which routinely uses this technique to estimate the strength of ocean surface winds and other surface phenomena from GPS reflections (Ruf et al, 2018). The technique is now widely known as GPS Reflectometry or GNSS Reflectometry. 


\begin{tabular}{|c|c|c|c|c|c|c|c|c|c|c|c|c|c|c|c|c|}
\hline $\begin{array}{l}\text { Observing } \\
\text { system }\end{array}$ & $\begin{array}{c}\text { Launch } \\
\text { Date }\end{array}$ & $\begin{array}{l}\text { Freq. } \\
\text { Band }\end{array}$ & $\begin{array}{l}\text { Phase } \\
\text { d } \\
\text { Array }\end{array}$ & $\begin{array}{l}\text { Multi- } \\
\text { Freq. }\end{array}$ & $\begin{array}{c}\mathrm{X}- \\
\text { Band }\end{array}$ & $\begin{array}{c}\text { Multi- } \\
\text { Pol }\end{array}$ & $\begin{array}{l}\text { Full } \\
\text { Pol }\end{array}$ & $\begin{array}{l}\text { Scan- } \\
\text { SAR }\end{array}$ & $\begin{array}{l}\text { Spot- } \\
\text { light }\end{array}$ & $\begin{array}{c}2-\mathrm{D} \\
\mathrm{OB} \\
\mathrm{P} \\
\end{array}$ & $\begin{array}{c}\text { AT } \\
\text { I }\end{array}$ & $\begin{array}{c}\text { Rapid } \\
\mathrm{Cal} / \mathrm{Val}\end{array}$ & $\begin{array}{c}\text { RPI for } \\
\text { Topo }\end{array}$ & $\begin{array}{c}\text { Pol- } \\
\text { InSAR }\end{array}$ & $\begin{array}{l}\text { System } \\
\text { Perf. }\end{array}$ & $\begin{array}{l}\text { GPS } \\
\text { Refl. }\end{array}$ \\
\hline Radarsat-1 & 1995 & $\mathrm{C}$ & & & & & & - & & & & & & & & \\
\hline SRTM & 2000 & $\mathrm{C}, \mathrm{X}$ & $\cdot$ & - & • & • & & & & & & & • & & & \\
\hline Envisat ASAR & 2002 & $\mathrm{C}$ & - & & & - & & - & & & & - & & & - & \\
\hline ALOS PalSAR & 2006 & $\mathrm{~L}$ & $\bullet$ & & & & $\bullet$ & & & & & & & $\bullet$ & & \\
\hline Radarsat-2 & 2007 & $\mathrm{C}$ & $\bullet$ & & & $\bullet$ & $\bullet$ & $\bullet$ & $\bullet$ & & $\bullet$ & $\bullet$ & - & $\bullet$ & & \\
\hline $\begin{array}{l}\text { COSMO/SkyMe } \\
\text { d }\end{array}$ & 2007 & $\mathrm{X}$ & $\bullet$ & & - & & & - & $\bullet$ & & & & & & & \\
\hline TerraSAR-X & 2007 & $\mathrm{X}$ & $\bullet$ & & $\bullet$ & $\bullet$ & & $\bullet$ & $\bullet$ & & & $\bullet$ & & $\bullet$ & & \\
\hline RISAT-2 & 2009 & $\mathrm{X}$ & & & • & $\bullet$ & & $\bullet$ & $\bullet$ & & & & & & $\bullet$ & \\
\hline TanDEM-X & 2010 & $\mathrm{X}$ & $\bullet$ & & - & • & & & & & • & • & • & • & & \\
\hline RISAT-1 & 2012 & $\mathrm{C}$ & $\bullet$ & & & & & & & & & & & & & \\
\hline KompSAT-5 & 2013 & $\mathrm{X}$ & $\bullet$ & & $\bullet$ & $\bullet$ & & $\bullet$ & $\bullet$ & & & & & & $\bullet$ & \\
\hline $\begin{array}{l}\text { ALOS PalSAR- } \\
2\end{array}$ & 2014 & $\mathrm{~L}$ & $\bullet$ & & & $\bullet$ & $\bullet$ & $\bullet$ & $\bullet$ & & & & & $\bullet$ & $\bullet$ & \\
\hline Sentinel-1A/B & $2014 / 16$ & $\mathrm{C}$ & $\bullet$ & & & $\bullet$ & & & & & & $\bullet$ & & & & \\
\hline SMAP & 2015 & $\mathrm{~L}$ & & & & $\bullet$ & & & & & & $\bullet$ & & & & $\bullet$ \\
\hline CyGNSS & 2016 & $\mathrm{~L}$ & & & & & & & & & & & & & & $\bullet$ \\
\hline ASNARO-2 & 2018 & $\mathrm{X}$ & & & • & $\bullet$ & & $\bullet$ & $\bullet$ & & & & & & $\bullet$ & \\
\hline NovaSAR-S & 2018 & $\mathrm{~S}$ & $\bullet$ & & & $\bullet$ & & $\bullet$ & & & & & & $\bullet$ & $\bullet$ & \\
\hline PAZ & 2018 & $\mathrm{X}$ & $\bullet$ & & $\bullet$ & $\bullet$ & & $\bullet$ & $\bullet$ & & & $\bullet$ & & $\bullet$ & & \\
\hline SAOCOM-1 & 2018 & $\mathrm{~L}$ & $\bullet$ & & & $\bullet$ & $\bullet$ & $\bullet$ & & & & & & & $\bullet$ & \\
\hline IceEye & 2018 & $\mathrm{X}$ & & & - & & & & & & & & & & • & \\
\hline Radarsat-RCM & 2019 & $\mathrm{C}$ & $\bullet$ & & & $\bullet$ & - & $\bullet$ & $\bullet$ & & & $\bullet$ & & - & $\bullet$ & \\
\hline
\end{tabular}

Table 2. Earth-orbiting, civil-use Microwave Remote Sensing systems flown since 1994 arranged by launch year - that exploit techniques first demonstrated by SIR-C/X-SAR (Farr et al, 2007; Ahmed et al, 1993; Ruf et al, 2018; Desnos et al, 2000; Shimada, 2009, Fox et al, 2002; Di Lazzarro et al, 2008; Werninghaus et al, 2004; eoportal, 2019; Krieger et al, 2005; Misra et al, 2006; Lee, 2010; Snoeij et al, 2010; Spencer et al, 2009; Yokota et al, 2013; Cohen et al, 2017; eoportal, 2019a; Frulla et al, 2011; Iceye, 2019; Seguin, 2005) 


\section{PREPRINT}

\section{SAR Systems after SIR-C/X-SAR}

In addition to the innovations discussed above, a lot of lessons were learned during the SIR-C/XSAR missions, which were freely and openly shared with the SAR community, e.g. (Freeman et al, 1996). The following addresses some of those lessons, and discusses their influence on the design of SAR missions that have flown after SIR-C/X-SAR, and others that are in the pipeline for the future (Table 3).

\subsection{Concept of Operations}

The concept of operations (ConOps) built around targeting supersites on each and every pass was incredibly valuable for $\mathrm{Cal} / \mathrm{Val}$ of the data and for testing out algorithms used to generate geophysical products. In some cases, however, a higher science return may have been possible, by using instead a "mow-the lawn" ConOps, a scenario in which area coverage is systematically built up by mosaicking together data strips acquired on successive orbit passes. This lesson was incorporated into the design of the JERS-1 Multi-Season Amazon Mapping Study (JAMMS) in 1995/6 (Siqueira et al, 2000; Rosenqvist et al, 2000), and the JPL mission design for the RADARSAT Antarctic Mapping Project in 1997 (Jezek et al, 1996; Jezek, 2008). And, of course, SRTM (Farr et al, 2007) and TanDEM-X (Krieger at al, 2007) and other systematic global mapping SAR missions have very successfully adopted this same "mow-the-lawn" approach (e.g., ALOS2 and Sentinel-1A/B).

\subsection{Platform Pointing}

The Space Shuttle Endeavour was in many respects an ideal platform for the SIR-C/X-SAR missions: power for payload operations was plentiful, the payload mass and volume allocations were huge, and the skill of the astronaut crew in flying "locked-down" orbit tracks between missions has already been noted. There was just one area where the platform's performance was less than optimal: pointing. The onboard Digital Autopilot was capable of controlling Space Shuttle pointing by the selection of different attitude and attitude rate deadbands (Galvez et al, 2019), and for SIR-C/X-SAR the preferred values were at the lower end: +/-1.0 degrees for attitude and +/-0.02 for attitude rate. Typical pointing knowledge requirements for today's SAR systems are one-tenth of the antenna beamwidth, which for SIR-C/X-SAR at C-band and X-band in the along-track (azimuth) dimension would have been 0.3 and 0.14 degrees, respectively. This discrepancy between desired and actual performance meant that SAR system engineers had to derive some very clever approaches using Doppler tracking - based on the SAR data itself - to determine, post-acquisition, where the SIR-C/X-SAR antennas were actually pointing (e.g. Chang and Curlander, 1992; Moreira 1992), which would allow the data to be properly processed. Today's free-flying spacecraft platforms have much better pointing knowledge and control, down to the milli-arcsecond level if necessary (Blackmore et al, 2011), obviating the need for most of the SAR data-based methods.

\subsection{Design of Polarimetric SAR systems}

Lessons learned on the design and calibration of spaceborne polarimetric SAR systems were captured in (Freeman, 2009), and have been applied to the design of a P-band (68 cm wavelength) 


\section{PREPRINT}

SAR designed to operate in orbit at Mars (Campbell et al, 2004; Campbell et al, 2004a), and also informed that of ESA's BIOMASS SAR system (Le Toan et al, 2011). Some SAR designers have begun to adopt compact or hybrid polarization architectures which have only two measurement channels (Raney and Freeman, 2009), but are almost as rich in information as full polarimetry, and allow for less constrained swath coverage than was the case for SIR-C/X-SAR. SIR-C/X-SAR data provided a 'gold standard' against which to test such approaches.

\subsection{Faraday rotation}

Because of the low altitude of the Shuttle platform, ionospheric propagation had no expected or noticeable effect on SIR-C/X-SAR measurements and on polarimetric SAR calibration in particular. Subsequent longer-wavelength SARs flying in higher orbits would have to adapt the algorithms used for SIR-C polarimetric calibration to deal with Faraday rotation effects, which can significantly distort the observed scattering matrix (Freeman and Saatchi, 2004; Freeman, 2004). SIR-C polarimetric data was used to simulate the effects of Faraday rotation and then the performance of algorithms to correct for them. Thanks to the openness of the Japanese ALOS PalSAR (and later ALOS PalSAR-2) team in sharing data and information about their system, viable approaches for polarimetric calibration that account for Faraday rotation were quickly identified and verified (Shimada et al, 2009; Freeman et al, 2009). Such techniques will prove invaluable again when the P-band (68 cm wavelength) BIOMASS polarimetric SAR system is launched in 2021 (Le Toan et al, 2011), which is expected to experience severe (many 10's of degrees) Faraday rotation, as well as other ionospheric distortion effects. These techniques will also help ensure rapid turnaround in calibrating polarimetric SAR measurements from the planned NISAR (JPL, 2019) and Tandem-L missions (Krieger et al, 2010; Moreira et al, 2015).

\subsection{Wide-swath, high-resolution systems}

The successful acquisition of ScanSAR data led to a breakthrough in providing wide-swath, and therefore more frequent, coverage of large regions of the Earth (Desnos et al, 2000; Fox et al, 2002). The key trade-off, known even before SIR-C/X-SAR, has always been that ScanSAR data yields only modest (typically $100 \mathrm{~m}$ or greater) spatial resolution. This will be remedied by future missions such as NISAR and Tandem-L, which have adopted a new technique developed by JPL and DLR, known as SweepSAR: a Scan-on-Receive architecture with a one-dimensional, phased array feed combined with a large (and lightweight) reflector antenna. SweepSAR permits wideswath data collection, while at the same time providing full polarimetry and fine spatial resolution of order 10 meters (Freeman et al, 2009a). Another technique, called Multiple Azimuth Phase Centers (MAPS), splits the antenna in the flight direction, so that each phase center is sampled by separate receivers. The additional samples allow for a reconstruction of the azimuth spectrum and control of ambiguities even at a lower Pulse Repetition Frequency (PRF) resulting in a wider echo window and swath width (Gebert et al, 2009).

\subsection{Smaller, lighter antennas}

With its huge dimensions of 12 meters X 4 meters, the SIR-C/X-SAR antenna is by far the largest civil-use SAR antenna flown to date. And the fact that it was a phased array at L- and C-band made it very heavy (3350 kg according to Jordan et al, 1995). A couple of questions the SAR designer 


\section{PREPRINT}

often has to answer are: can you make the antenna smaller, and lighter? SIR-C data collected at very high look angles (63 degrees) helped answer the first question with a qualified yes (Freeman et al, 2000). The answer to the second question is also yes, but one has to give up some performance in either spatial resolution or ground swath (or both). With that proviso, it is certainly possible to design a SAR system that fits within a Smallsat form factor $(<300 \mathrm{~kg}$ total mass), and take advantage of the ongoing revolution in miniaturizing spacecraft (Freeman, 2018). Commercial operators like Finland's IceEye and Japan's NEC Corporation have already demonstrated and put this into practice with Smallsat SARs on orbit that are returning quality SAR images (Yokota et al, 2013; Iceye, 2019), and more are on the way (Saito et al, 2018; Capella Space 2019). The trend thus far has resulted in X-band SAR systems that provide high-resolution (a few meters), singlepolarization imagery in all weathers, and longer wavelength systems are under consideration (Freeman and Chahat, 2017).

\subsection{On-Board Processing}

One of the innovations demonstrated during SIR-XC/X-SAR that remains under-exploited is onboard SAR processing (Tables 2 and 3). There are several explanations that can account for this lack of adoption. The first is that to preserve the full phase coherence in the data (for use in RPI for example), there is often not much (if any) data reduction from the 'raw' (as acquired) data format to the fully processed (complex) SAR image. Secondly, science users of SAR data often insist on each and every bit of the data collected being returned, so they can squeeze every last drop of science value from it. Thirdly, having access to the raw data does give flexibility in the format and quality of the final image product, in terms of number of looks, spatial resolution, geometric projection, calibration, etc. Finally, onboard processors with the appropriate throughput capacity have, until recently, been relatively expensive, massive and power-hungry.

The tide may yet turn for OBP on Earth-orbiting SARs as smaller, lightweight processors become available, and Smallsat SAR operators focus their attention on more application-oriented users, who have more interest in the information SAR systems can provide, than in the data itself. JPL (in collaboration with DLR and ASI) have recently proposed the VERITAS Venus-orbiting science mission, which would carry an InSAR payload known as VISAR (Hensley et al, 2015). With a fixed baseline similar to SRTM (but much shorter), VISAR's two SAR antennas would collect Single-Pass Interferometric SAR data, and use OBP to reduce it to the level of an interferogram (Figures 8 and 9), which can be spatially averaged (multi-looked) to reduce the data volume dramatically (by a factor of up to a 1000). For planetary scientists this modification of the raw SAR data is seen as not just acceptable, but highly desirable, since it would result in the return of the highest-value data set - global surface topography at similar spatial scales to SRTM - to help them fill in the missing pieces in the evolution of Venus' surface (Freeman and Smrekar, 2015).

\subsection{Tomography}

Building on the successful demonstration of PolInSAR using SIR-C/X-SAR data, DLR have introduced an entirely new technique called SAR Tomography, which can be thought of as PolInSAR with multiple baseline separations. SAR Tomography provides much better insights into the 3-D structure of vegetation canopies, resolving several different scattering layers at 


\section{PREPRINT}

multiple heights (Reigber and Moreira, 2000). With enough spatial resolution, SAR Tomography can also be used to reveal the complex 3-D structure of urban terrain, as demonstrated using TanDEM-X data (Fornaro et al, 2012). Tandem-L will feature tomography as an operational technique, that will be used to derive 3-D structure information in forests and ice (Moreira et al, 2015).

\subsection{Signals-of-Opportunity}

Another under-exploited innovation resulting from SIR-C/X-SAR (Table 3) is the use of reflected Signals-of-Opportunity such as GPS to measure variations in geophysical properties of the Earth's surface (Lowe et al, 2002). NASA's CyGNSS mission (Ruf et al, 2018), which consists of 8 Smallsats flying in a 'string-of-pearls' formation, each mounted with GPS receivers on the top and bottom (nadir) decks of the spacecraft, has demonstrated the promise of this new remote sensing technique. Signals-of-Opportunity from existing microwave satellite transmissions cover all parts of the Radio Frequency spectrum, and open up the possibility of high temporal frequency measurements of geophysical parameters such as Soil Moisture; Sea Surface Height; Ocean Vector Winds; Snow Water Equivalent; Root Zone Soil Moisture; and Vegetation Water Content (Shah et al, 2018). NASA recently selected the SigNals-Of-Opportunity P-band Investigation (SNoOPI) - a cubesat project pathfinder for measuring two of these environmental parameters using reflected P-band Signals-of-Opportunity (Purdue, 2019).

\begin{tabular}{|c|c|c|c|c|c|c|c|c|c|c|c|c|c|c|c|c|}
\hline $\begin{array}{l}\text { Observing } \\
\text { system }\end{array}$ & $\begin{array}{c}\text { Nominal } \\
\text { Launch } \\
\text { Date }\end{array}$ & $\begin{array}{l}\text { Freq. } \\
\text { Band }\end{array}$ & $\begin{array}{l}\text { Phased } \\
\text { Array }\end{array}$ & $\begin{array}{l}\text { Multi } \\
\text {-Freq. }\end{array}$ & $\begin{array}{c}\mathrm{X}- \\
\text { band }\end{array}$ & $\begin{array}{c}\text { Multi } \\
\text {-Pol }\end{array}$ & $\begin{array}{l}\text { Full } \\
\text { Pol }\end{array}$ & $\begin{array}{l}\text { Scan- } \\
\text { SAR }\end{array}$ & $\begin{array}{l}\text { Spot- } \\
\text { light }\end{array}$ & $\begin{array}{l}2-\mathrm{D} \\
\text { OBP }\end{array}$ & ATI & $\begin{array}{c}\text { Rapid } \\
\text { Cal/Val }\end{array}$ & $\begin{array}{c}\text { RPI } \\
\text { for } \\
\text { Topo }\end{array}$ & $\begin{array}{c}\text { Pol- } \\
\text { InSAR }\end{array}$ & $\begin{array}{l}\text { System } \\
\text { Perf. }\end{array}$ & $\begin{array}{l}\text { GPS } \\
\text { Refl. }\end{array}$ \\
\hline $\begin{array}{l}\text { Cosmo/Sky } \\
\text { Med G2 }\end{array}$ & 2019 & $\mathrm{X}$ & $\cdot$ & & $\cdot$ & - & - & - & $\cdot$ & & & & & & $\cdot$ & \\
\hline MicroXSAR & 2020 & $\mathrm{X}$ & & & $\cdot$ & & & & - & & & & & & - & \\
\hline KompSAT-6 & 2020 & $\bar{X}$ & $\bullet$ & & $\cdot$ & $\cdot$ & & $\cdot$ & $\cdot$ & & & $\cdot$ & & $\cdot$ & & \\
\hline BIOMASS & 2021 & $\mathrm{P}$ & & & & & $\cdot$ & & & & & $\bullet$ & & $\bullet$ & $\bullet$ & \\
\hline NISAR & 2021 & $\mathrm{~S}, \mathrm{~L}$ & & $\bullet$ & & $\bullet$ & $\bullet$ & $\bullet$ & & & & $\bullet$ & & $\bullet$ & $\bullet$ & \\
\hline ALOS-4 & 2021 & $\mathrm{~L}$ & $\bullet$ & & & $\cdot$ & $\cdot$ & $\bullet$ & $\bullet$ & & & & & $\bullet$ & $\bullet$ & \\
\hline $\begin{array}{l}\text { Sentinel- } \\
1 \mathrm{C} / \mathrm{D}\end{array}$ & $2022 / 23$ & $\mathrm{C}$ & $\bullet$ & & & $\bullet$ & & & & & & $\bullet$ & & & $\bullet$ & \\
\hline Tandem-L & 2025 & $\mathrm{~L}$ & & & & $\bullet$ & $\bullet$ & $\bullet$ & & & $\bullet$ & $\bullet$ & & $\bullet$ & $\bullet$ & \\
\hline SNoOPI & 2022 & $\mathrm{P}$ & & & & & & & & & & & & & & $\bullet$ \\
\hline VERITAS & 2025 & $\mathrm{X}$ & . & & $\cdot$ & & & & & $\cdot$ & & & & & $\cdot$ & \\
\hline HRWS & 2025 & $\mathrm{X}$ & $\bullet$ & & $\bullet$ & $\cdot$ & $\cdot$ & $\bullet$ & $\bullet$ & & $\cdot$ & $\bullet$ & & & $\bullet$ & \\
\hline $\begin{array}{l}\text { Mars P-band } \\
\text { SAR }\end{array}$ & 2028 & $\mathrm{P}$ & & & & $\bullet$ & $\bullet$ & & & & & & & & $\bullet$ & \\
\hline
\end{tabular}

Table 3. Microwave Remote Sensing systems in the planning or development stages (organized by nominal launch year) that make use of techniques first demonstrated by SIR-C/X-SAR. 


\section{PREPRINT}

\section{Summary and Discussion}

The legacy of SIR-C/X-SAR has had a profound impact on today's active microwave remote sensing systems, SARs in particular, which is expected to continue on into the future. The science results from the two flights in 1994 laid down the fundamentals for characterizing the surface of the Earth using SAR systems, serving as a foundation for analysis of data produced by the many satellites now in operation (Table 2). The missions introduced a series of innovations that have been incorporated into the design of today's SAR systems, and in some cases improved upon.

Looking ahead, we appear to have reached a fork in the road, with three branches. The first branch leads to multi-mode systems utilizing phased array technology in relatively complex, adaptive systems like Sentinel-1, ALOS-2, Radarsat RCM, NISAR, and Tandem-L, flying on a handful of fairly large, dedicated platforms. The second branch heads off towards simpler systems that embrace the Smallsat paradigm, each with less capability, that can be deployed in constellations of 10 or more to deliver increased temporal revisit frequency, or multi-static imaging capability. The third branch points in the direction of Signals-of-Opportunity systems receiving signals from a multitude of RF sources in orbit, that fit on very small satellites, and can be deployed as constellations in very large numbers. These three branches are not mutually exclusive - they can all co-exist, since there will likely be relatively little overlap in the science and applications they address, each serving different purposes.

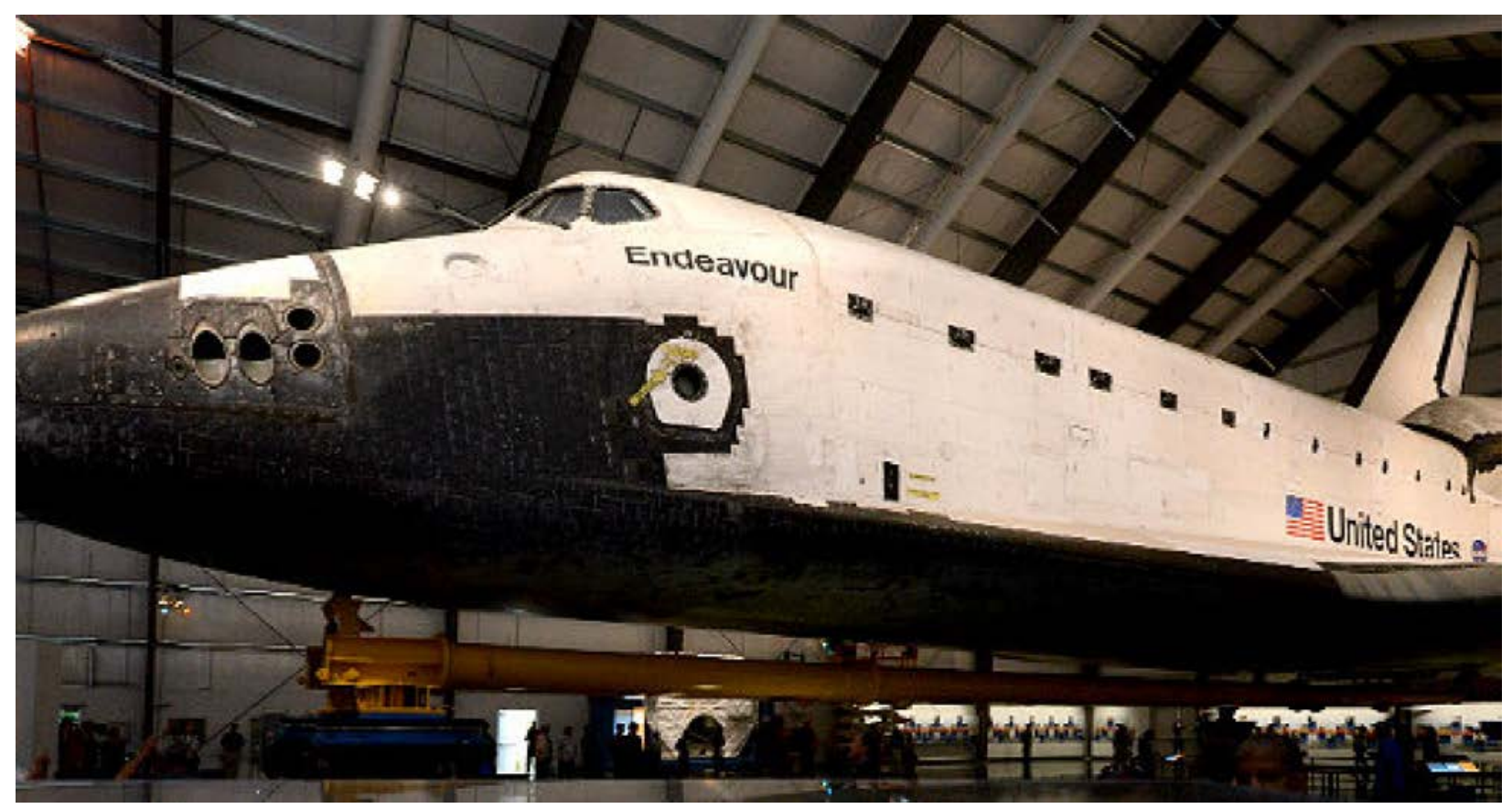

Figure 11: The Space Shuttle Endeavour, the platform that hosted the SIR-C/X-SAR system on both flights in 1994, has retired to its new home at the Los Angeles Science Museum.

The elements that made the SIR-C/X-SAR mission a success are now scattered to the four winds: the huge SAR antennas and the radar electronics are in storage, the Space Shuttle Endeavour found a home at the Los Angeles Science Museum (Figure 11), and the scientists and engineers who worked on the project have long since moved on to new pastures. But the most important piece of 
the system lives on - the data, which is still accessible through the long-term archive at the U.S. Geological Survey (USGS)'s Earth Resources Observation and Science (EROS) Center (USGS, 2019) and at DLR's Earth Observation Center (DLR, 2019).

\section{Acknowledgments}

This article is dedicated to our departed colleague Rolando Jordan, who was the lead radar systems engineer for SIR-C, and is missed by all of us. The authors would also like to express their special appreciation for the efforts of Charles Elachi at JPL and Herwig Öttl at DLR, for their vision in conceiving SIR-C/X-SAR as a joint venture, and a follow-on to the earlier Shuttle radars. We would also like to acknowledge the excellent work done by the many scientists who have used SIR-C/X-SAR data in their research, and the many engineers who labored to deliver the success of both missions in 1994. Part of the work described in this paper was carried out at the Jet Propulsion Laboratory, California Institute of Technology, under a contract with the National Aeronautics and Space Administration. Support for the German Aerospace Center was provided by the German government. 


\section{PREPRINT}

\section{References}

Abdelsalam, M. G., and Stern, R. J., 1996. Mapping Precambrian structures in the Sahara Desert with SIR-C/X-SAR radar: The Neoproterozoic Keraf Suture, NE Sudan, JGR Planets, Vol. 101, Issue E10, 23063-23076. DOI: 10.1029/96JE01391

Ahmed, S. Parashar, S., Langham, E., McNally, J., 1993, RADARSAT Mission Requirements and Concept, Canadian Journal of Remote Sensing, Vol. 19, No. 4.

Albright, T. P., et al, 1998. Classification of surface types using SIR-C/X-SAR, Mount Everest Area, Tibet, JGR Planets, Vol. 103, Issue E11, 25823-25837. DOI: 10.1029/98JE01893

Alsdorf, D. E., Smith, L.C. , and Melack, J. M., 2001 . Amazon floodplain water level changes measured with interferometric SIR-C radar. IEEE Trans. Geosci. Remote Sensing, Vol, 39, 2 , $423-431$.

Attema, E., Desnos, Y-L., Duchossois, G., 2000. Synthetic Aperture Radar in Europe: ERS, Envisat and Beyond, Johns Hopkins APL Technical Digest, Vol. 21, No. 1.

Bamler, R., 1995. Optimum look weighting for burst-mode and ScanSAR processing, IEEE Trans. Geosci. Remote Sens., Vol. 33, no. 3, 722- 725.

Beal, R. C., Oden, S.F., and McArthur, J. L., 1991. A real-time SAR processor for ocean wave spectra, Proc. IGARSS 1991, Espoo, Helsinki, Finland.

Beal, R. C., and Monaldo, F. M., 1995. Real-time Observations of Southern Ocean Wave Fields form the Shuttle Imaging Radar. IEEE Trans. on Geoscience and Remote Sensing, Vol. 33, No. 4, 942-949.

Bergen, K. M., et al, 1998. Characterizing Carbon in a Northern Forest by Using SIR-C/X-SAR Imagery, Remote Sensing of Environment, Vol. 63, Issue 1, 24-39, DOI: 10.1016/S00344257(97)00103-X.

Blackmore, L., et al, 2011. Instrument Pointing Capabilities: Past, Present and Future, AAS Guidance and Control Conference, Breckenridge, Colorado.

Bueso-Bello, J. L. et al., 2017. Performance analysis of TanDEM-X quad-polarization products in pursuit monostatic mode, IEEE J. Sel. Topics Appl. Earth Observ. Remote Sens., Vol. 10, No. 5, 1853-1869.

Campbell, B.A., A. Freeman, L. Veilleux, B. Huneycutt, M. Jones, R. Shotwell, 2004. A P-band radar mission to Mars. Proc. IEEE Aerospace Conference, Big Sky, MT.

Campbell, B.A., T. Maxwell, and A. Freeman, 2004a. Mars orbital SAR: Obtaining geologic information from radar polarimetry, J. Geophys. Res., 109, doi:10.1029/2004JE002264.

Capella Space, 2019. https://www.capellaspace.com (accessed 22 March, 2019)

Chang, C. Y. and Curlander, J. C., 1992. Application of the multiple PRF technique to resolve Doppler centroid estimation ambiguity for spaceborne SAR, IEEE Trans. on Geoscience and Remote Sensing, Vol. 30, Issue 5, 941 - 949. DOI: 10.1109/36.175329.

Chang, C. Y., Jin. M. Y., Lou. Y-L, and Holt, B., 1995. First SIR-C ScanSAR Results, IEEE Trans. on Geoscience and Remote Sensing, Vol. 34, No. 5, 1278-1281.

Chen, F., Lasaponara, R, and Masini, M., 2015. An overview of satellite synthetic aperture radar remote sensing in archaeology: From site detection to monitoring, Journal of Cultural Heritage, DOI: 10.1016/j.culher.2015.05.003

Cimino, J., Elachi, C., \& Settle, M., 1986. SIR-B-The 2nd shuttle imaging radar experiment. IEEE Transactions on Geoscience and Remote Sensing. 24(4), 445-452.

Cloude, S., and Pottier, E., 1996. A Review of Target Decomposition Algorithms in Radar Polarimetry, IEEE Trans. on Geoscience and Remote Sensing, Vol. 34, No. 2, 498-518. 


\section{PREPRINT}

Cloude, S. R., and Papathanassiou, K. P., 1998. Polarimetric SAR Interferometry, IEEE Trans. on Geoscience and Remote Sensing, Vol. 36, No. 5, 1551-1565.

Cloude, S. R., Corr, D.G., and Williams, M.L., 2003 . Target detection beneath foliage using polarimetric synthetic aperture radar interferometry. Waves in Random Media , 2 , S393 S414, DOI: 10.1088/0959-7174/14/2/015

Cohen, M., et al, 2017. NovaSAR-S Low Cost Spaceborne SAR Payload Design, development and deployment of a new benchmark in spaceborne radar, IEEE Radar Conference, Seattle, WA.

Coltelli, M., et al, 1996. SIR-C/X-SAR multifrequency multipass interferometry: A new tool for geological interpretation, JGR, Vol. 101, No. E10, 23,127-23,148.

Dabbagh, A. E., Al-Hinai, A Khattab G., sif Khan, M., 1997. Detection of sand-covered geologic features in the Arabian Peninsula using SIR-C/X-SAR data, Remote Sensing of Environment, Volume 59, Issue 2, 375-382, DOI: 10.1016/S0034-4257(96)00160-5.

de Zan, F., Monti Guarnieri, A., 2006. TOPSAR: Terrain Observation by Progressive Scans, IEEE Trans. Geosci. Remote Sens., Vol. 44, No. 9, 2352-2360.

Desnos, Y-L., et al, 2000. ASAR - Envisat's Advanced Synthetic Aperture Radar, ESA Bulletin 102.

Di Lazzaro, M., Angino, G., Piemontese, M., Capuzi, A., Leonardi, R., 2008. COSMO-SkyMed: The Dual-Use Component of a Geospatial System for Environment and Security, Proceedings of the 2008 IEEE Aerospace Conference, Big Sky, MT, USA.

Dieterle, G., Schlude, F., 1982. The European MRSE-Project on the first Spacelab Flight, Proc. IGARSS'82, Munich, Germany.

DLR, 2019. X-SAR Data Archive. https://geoservice.dlr.de/egp/ (accessed 22 March 2019)

Dobson, M. C., et al, 1995. Estimation of forest biophysical characteristics in Northern Michigan with SIR-C/X-SAR. IEEE Trans. on Geoscience and Remote Sensing, Vol. 33, No. 4, 877895.

Dubois, P. C., van Zyl, J. J., and Engman, T., 1995. Measuring Soil Moisture with Imaging Radars. IEEE Trans. on Geoscience and Remote Sensing, Vol. 33, No. 4, 915-926.

Elachi, C., Brown, W. E., Cimino, J. B., Dixon, T., Evans, D. L., Ford, J. P., et al., 1982. Shuttle imaging radar experiment. Science, 218, 996-1004.

eoportal, 2019. RISAT-2 (Radar Imaging Satellite-2). https://earth.esa.int/web/eoportal/satellitemissions/r/risat-2 (accessed 22 March, 2019)

eoportal, 2019a. PAZ SAR satellite mission of Spain https://directory.eoportal.org/web/eoportal/satellite-missions/p/paz (accessed $22 \mathrm{March}$, 2019).

Evans, D. L., Plaut, J. J. and Stofan, E. R., 1997. Overview of the Spaceborne Imaging RadarC/X-band Synthetic Aperture Radar (SIR-C/X-SAR) missions, Remote Sensing of Environment, Volume 59, Issue 2, 135-140, DOI: 10.1016/S0034-4257(96)00152-6.

Evans, D. E., et al, 2005. Seasat-A 25-year legacy of success. Remote Sensing of Environment $94,384-404$

Evans, D. L., 2006. Spaceborne imaging radar-C/X-band synthetic aperture radar (SIR-C/XSAR): a look back on the tenth anniversary, IEE Proceedings - Radar, Sonar and Navigation, Volume 153, Issue 2, April 2006, 81 - 85, DOI: 10.1049/ip-rsn:20045095.

Fang, Y., and Moore, R. K., 1997. Inflight vertical antenna patterns for SIR-C from Amazon rain-forest observations, Remote Sensing of Environment, Volume 59, Issue 2, 407-414, DOI: $10.1016 / \mathrm{S} 0034-4257(96) 00163-0$. 


\section{PREPRINT}

Farr , T. G. and Kobrick, M., 2000. The shuttle radar topography mission. EOS Trans. Am. Geophys. Union , Vol. 81, Issue48, 583-585, DOI: 10.1029/EO081i048p00583

Farr, Tom G.; Rosen, Paul A.; Caro, Edward; Crippen, Robert; Duren, Riley; Hensley, Scott; Kobrick, Michael; Paller, Mimi; Rodriguez, Ernesto; Roth, Ladislav; Seal, David; Shaffer, Scott; Shimada, Joanne; Umland, Jeffrey; Werner, Marian; Oskin, Michael; Burbank, Douglas; Alsdorf, Douglas, 2007. The Shuttle Radar Topography Mission. Reviews of Geophysics. 45 (2): RG2004.

Ferrazzoli, P, et al, 1997. The potential of multifrequency polarimetric SAR in assessing agricultural and arboreous biomass. IEEE Trans. Geosci. Remote Sensing, 1 , 5 - 17, DOI: $10.1109 / 36.551929$.

Floricioiu, D. and Rott, H., 2001. Seasonal and short-term variability of multifrequency, polarimetric radar backscatter of Alpine terrain from SIR-C/X-SAR and AIRSAR data, IEEE Transactions on Geoscience and Remote Sensing, Vol. 39 , Issue 12, 2634 - 2648. DOI: $10.1109 / 36.974998$

Foody, g. M., et al, 1997. Observations on the relationship between SIR-C radar backscatter and the biomass of regenerating tropical forests, International Journal of Remote Sensing, Vol. 18, Issue 3, 687-694. DOI: 10.1080/014311697219024

Fornaro, G., et al, 2012. SAR Tomography: An Advanced Tool for 4D Spaceborne Radar Scanning with Application to Imaging and Monitoring of Cities and Single Buildings, IEEE Geoscience and Remote Sensing Society Newsletter.

Forster, R. R., Isacks, B. L. and Das, S. B., 1996. Shuttle imaging radar (SIR-C/X-SAR) reveals near-surface properties of the South Patagonian Icefield, JGR Planets, Vol. 101, Issue E10, 23169-23180. DOI: 10.1029/96JE01950

Fox, P. Luscombe, A. P., Ali, Z., 2002. The Radarsat-2 Mission, New Modes and Techniques, Proceedings of IAC (International Astronautical Congress), Houston, Tx.

Freeman, A., Durden, S.D., and Zimmermann, R., 1992. Mapping Sub-tropical Vegetation using Multi-frequency Multi-polarization SAR data, Proc. IGARSS '92, Houston Texas.

Freeman, A., Cruz, J., Alves, M., Chapman, B., S. Shaffer and Turner, E., 1994. SIR-C Calibration Results, in Proc. IGARSS '94, Pasadena, California.

Freeman, A., Cruz, J., Alves, M., Chapman, B., S. Shaffer and Turner, E., SIR-C Data Quality and Calibration Results, 1995. IEEE Trans. on Geoscience and Remote Sensing, vol. 33, no. 4, 848-857.

Freeman, A., E. Caro, R. Jordan, Y. Kim, J. Klein, Y. Lou, Y. Shen, S, Shaffer, C.Y. Chang and F. Stuhr, 1996. Lessons learned from the first two SIR-C missions - an engineering perspective, Proc. EUSAR ‘96, Königswinter, Germany, 37-40.

Freeman, A. and Durden, S., 1998. A Three-Component Scattering Model for Polarimetric SAR Data, IEEE Trans. on Geoscience and Remote Sensing, Vol. 36, No. 3, 963-973.

Freeman, A., W. T. K. Johnson, B. Honeycutt, R. Jordan, S. Hensley, P. Siqueira, and J. Curlander, 2000. The Myth of the Minimum SAR antenna area constraint, IEEE Trans. Geosci. Remote Sensing, vol. 38, 320-324.

Freeman, A. and Saatchi, S., 2004. On the Detection of Faraday Rotation in Linearly Polarized, L-Band SAR Backscatter Signatures, IEEE Transactions on Geoscience and Remote Sensing, vol. 42, no. 8, 1607-1616.

Freeman, A., 2004. Calibration of Linearly Polarized Polarimetric SAR Data Subject to Faraday Rotation, IEEE Transactions on Geoscience and Remote Sensing, vol. 42, no. 8, 1617-1624. 


\section{PREPRINT}

Freeman, A., Pi, X. and Chapman, B., Calibration of PalSAR polarimetric data, Proc. PolinSAR 2009, Frascati, Italy.

Freeman, A., 2009. On the Design of Spaceborne Polarimetric SARs, Proc. Radarcon '09, Pasadena, CA.

Freeman, A., G. Krieger, P. Rosen, Younis, M., W. T. K. Johnson, Huber, S., R. Jordan, and Moreira, A., 2009a. SweepSAR: Beam-forming on Receive using a Reflector-Phased Array Feed Combination for Spaceborne SAR, Proc. Radarcon '09, Pasadena, CA.

Freeman, A. and Smrekar, S., 2015. VERITAS - a Discovery-class Venus surface geology and geophysics mission, 11th Low Cost Planetary Missions Conference, Berlin, Germany.

Freeman, A. and Chahat, N., 2017. S-Band Smallsat InSAR constellation for surface deformation science, Radar Conference (RadarCon), May 2017 IEEE, 0867-0872

Freeman, A. 2018. Design Principles for Smallsat SARs. SSC18-V-01, Smallsat Conference, Logan Utah.

Frulla, L., et al, 2011. SAOCOM Mission Overview, 2011 CEOS SAR Calibration and Validation Workshop Fairbanks, AK.

Fujita, M., et al, 1998. Polarimetric calibration of the SIR-C C-band channel using active radar calibrators and polarization selective dihedrals, IEEE Trans. on Geoscience and Remote Sensing, Vol. 36, Issue 6, 1872 - 1878. DOI: 10.1109/36.729358.

Gade, M., Alpers, W., Huhnerfuss, H., Masuko, H., Kobayashi, T., 1998. Imaging of biogenic and anthropogenic ocean surface films by the multifrequency/multipolarization SIR-C/XSAR, JGR Oceans, vol. 103, issue C9, DOI: 10.1029/97JC01915.

Galvez, R., Gaylor, S., Young, C., Patrick, N., Johnson, D., and Ruiz, J., 2019. The Space Shuttle and Its Operations, https://www.nasa.gov/centers/johnson/pdf/584722main_Wingsch3a-pgs53-73.pdf (accessed 25 March 2019).

Gebert, N., Krieger, G., and Moreira, A., 2009. Digital beamforming on receive: Techniques and optimization strategies for high-resolution wide-swath SAR imaging. IEEE Transactions on Aerospace and Electronic Systems, 45.2, 564-592.

Geudtner, D., Zink, M., Gierull, C., and Shaffer, S., 2002. Interferometric Alignment of the XSAR Antenna System on the Space Shuttle Radar Topography Mission, IEEE Trans. on Geoscience and Remote Sensing, vol. 40, no. 5, 995-1006.

Greeley, R., and Blumberg, D., 1995. Preliminary Analysis of Shuttle Radar Lab (SRL-1) Data to Study Aeolian Features and Processes. IEEE Trans. on Geoscience and Remote Sensing, Vol. 33, No. 4, 927-933.

Gunter's Space Page, 1964. Quill (P-40). https://space.skyrocket.de/doc_sdat/quill.htm (accessed 21 March, 2019).

Guo, H., et al, 1996. Detection of structural and lithological features underneath a vegetation canopy using SIR-C/X-SAR data in Zhao Qing test site of southern China, JGR Planets, Vol. 101, Issue E10, 23101-23108. DOI: 10.1029/96JE01974

Harrell, P. A, Kasischke, E. S., Bourgeau-Chavez, L. L., Haney, E. M. and Christensen, N. L., 1997. Evaluation of approaches to estimating aboveground biomass in Southern pine forests using SIR-C data, Remote Sensing of Environment, Volume 59, Issue 2, 223-233, DOI: 10.1016/S0034-4257(96)00155-1.

Hensley, S., S. Smrekar, S. Shaffer, M. Paller, H. Figueroa, A. Freeman, R. Hodges, P. Walkemeyer, 2015. VISAR: A Next Generation Interferometric Radar for Venus Exploration, Venus Lab and Technology Workshop, Houston, TX. 


\section{PREPRINT}

Hess, L. L. Melack, J.M., Filoso, S. ; Wang, Y., 1995. Delineation of inundated area and vegetation along the Amazon floodplain with the SIR-C synthetic aperture radar. IEEE Trans. on Geoscience and Remote Sensing, Vol. 33, No. 4, 896-904.

Hess, L. L. and Melack, J.M., 2003. Remote sensing of vegetation and flooding on Magela Creek Floodplain (Northern Territory, Australia) with the SIR-C synthetic aperture radar. Hydrobiologia Vol. 500, 65 - 82, DOI: 10.1023/A:1024665017985

Holt, B., 1998. Introduction to special section: Studies of the ocean surface from the Spaceborne Imaging Radar-C/X-Band SAR experiments, Journal of Geophysical Research: Oceans, vol. 103, issue C9, DOI: 10.1029/98JC01618.

Huadong, G., Jingjuan, L., Changlin, W., Chao, W., Farr, T. G., Evans, D. L., 1997. Use of multifrequency, multipolarization shuttle imaging radar for volcano mapping in the Kunlun Mountains of Western China, Remote Sensing of Environment, Volume 59, Issue 2, 364374, DOI: 10.1016/S0034-4257(96)00175-7.

Iceye, 2019. Iceye Global Satellite Monitoring. https://www.iceye.com (accessed 22 March, 2019)

Jameson, A. R., Li, Fuk K. Durden, S. L., Haddad, Z. S., Holt, B., Fogarty, T., Im, E. and Moore, R. K., 1997. SIR-C/X-SAR observations of rain storms, Remote Sensing of Environment, Volume 59, Issue 2, 267-279, DOI: 10.1016/S0034-4257(96)00159-9.

Jezek, K.C., J. Curlander, L. Norikane, F. Carsey, J. Crawford, C. Wales and J. Muller, 1996. RADARSAT: The Antarctic Mapping Project. Geoscience and Remote Sensing Symposium Proceedings, IGARSS '96, v. 3, 1775-1776, 1996

Jezek, K. C., 2008. The RadarSAT-1 Antarctic Mapping Project, Byrd Polar Research Center, Report No. 22, ISSN: 0896-2472.

Jordan, R. L., Huneycutt, B. L., and Werner, M., 1995. The SIR-C/X-SAR Synthetic Aperture Radar System. IEEE Trans. on Geoscience and Remote Sensing, Vol. 33, No. 4, 829-839.

JPL, 2019. NASA-ISRO SAR Mission (NISAR). https://nisar.jpl.nasa.gov/ (accessed 22 March 2019).

Kasischke, E. S., Melack, J. M., and Dobson, M. C., 1997. The use of imaging radars for ecological applications, A review, Remote Sensing of Environment, Volume 59, Issue 2, 141-156, DOI: 10.1016/S0034-4257(96)00148-4.

Krieger, G., Moreira, A., Hajnsek, I., Werner, M., Fiedler, H., Settelmeyer, E., 2005. The TanDEM-X Mission Proposal, Proceedings of the ISPRS Hannover Workshop 2005, Hannover, Germany.

Krieger, G., Moreira, A., Fiedler, H., Hajnsek, I., Werner, M., Younis, M., Zink, M., 2007. TanDEM-X: A Satellite Formation for High Resolution SAR Interferometry. IEEE Transactions on Geoscience and Remote Sensing, Vol. 45, No. 11, 3317-3341.

Krieger, G., Irena Hajnsek, Konstantinos Papathanassiou, Michael Eineder, Marwan Younis, Francesco De Zan, Sigurd Huber, Paco Lopez-Dekker, Pau Prats, Marian Werner, Yuhsyen Shen, Anthony Freeman, Paul Rosen, Scott Hensley, W Johnson, Louise Veilleux, Bernhard Grafmueller, Rolf Werninghaus, Richard Bamler, Alberto Moreira, 2010. Tandem-L: An innovative interferometric and polarimetric SAR mission to monitor earth system dynamics with high resolution, IGARSS 2010, Hawaii, 253-256.

Kruse, F., 1996. Geologic mapping using combined analysis of Airborne Visible/Infrared Imaging Spectrometer (AVIRIS) and SIR-C/X-SAR data, Proc. SPIE 2819, Imaging Spectrometry II, DOI: 10.1117/12.258078. 


\section{PREPRINT}

Kusky, T. M. and Ramadan, T. M., 2002. Structural controls on Neoproterozoic mineralization in the South Eastern Desert, Egypt: an integrated field, Landsat TM, and SIR-C/X SAR approach, Journal of African Earth Sciences, Vol. 35, Issue 1, 107-121, DOI: 10.1016/S0899-5362(02)00029-5

Lanari, R., et al., 1996. Generation of digital elevation models by using SIR-C/X-SAR multifrequency two-pass interferometry: the Etna case study, IEEE Trans. on Geoscience and remote Sensing, Vol. 34 , Issue 5, 1097 - 1114. DOI: 10.1109/36.536526

Lanari, R., Tesauro, M., Sansosti, E., and Fornaro, G., 2001. Spotlight SAR Data Focusing Based on a Two-Step Processing Approach, IEEE Trans. on Geoscience and Remote Sensing, Vol. 39, No. 9, 1993-2004.

Le Toan, T., et al, 2011. The BIOMASS mission: Mapping global forest biomass to better understand the terrestrial carbon cycle, Remote Sensing of Environment, Vol. 115, Issue 11, 2850-2860.

Lee, J-S., et al, 2000. A new technique for noise filtering of SAR interferometric phase images, IEEE Trans. on Geoscience and remote Sensing, Vol. 36 , Issue 5, 1456 - 1465. DOI: $10.1109 / 36.718849$.

Lee, S-R., 2010. Overview of KOMPSAT-5 Program, Mission, and System, Proceedings of IGARSS (IEEE International Geoscience and Remote Sensing Symposium) 2010, Honolulu, HI, USA.

Li, X.W., Guo, H.D., Wang, C.L., Li, Z., and Liao, J.J., 2003. DEM generation in the densely vegetated area of Hotan, north-west China using SIR-C repeat pass polarimetric SAR interferometry. Int. J. Remote Sens., 14 , 2997 - 3003, DOI: 10.1080/0143116031000094773

Lowe, S. T., LaBrecque, J. T., Zuffada, C., Romans, L.J., Young, L.E., and Hajj, G. A., 2002. First spaceborne observation of an Earth-reflected GPS signal Radio Science, Volume: 37 , Issue: 1.

Macelloni, G. et al, 1999. The SIR-C/X-SAR experiment on Montespertoli: Sensitivity to hydrological parameters, International Journal of Remote Sensing, Vol. 20, Issue 13, 2597 2612. DOI: $10.1080 / 014311699211958$

MacKay, M. E., Mouginis-Mark, P. J., 1997. The effect of varying acquisition parameters on the interpretation of SIR-C radar data: The Virunga volcanic chain, Remote Sensing of Environment, Vol. 59, Issue 2, 321-336, DOI: 10.1016/S0034-4257(96)00144-7.

MacKay, M., Rowland, S., Mouginis-Mark, P. et al., 1998. Thick lava flows of Karisimbi Volcano, Rwanda; insights from SIR-C interferometric topography, Bull Volcanol. 60: 239 251. https://doi.org/10.1007/s004450050230

Macklin, J. T. and Stapleton, N. R., 1998. Radar backscatter statistics from the sea surface: Implications of SIR-C/X-SAR observations from the NE Atlantic, Journal of Geophysical Research: Oceans, vol. 103, issue C9, DOI: 10.1029/97JC03423.

Mango, S., et al, 1995. Remote sensing of current-wave interactions with SIR-C/X-SAR during SRL-1 and SRL-2 at the Gulf Stream Supersite, Proc. IGARSS '95, Florence, Italy.

Masuko, H., Kobayashi, T., Okamoto, K.-I. and W. Alpers, W., 1995. Observation of artificial slicks with SIR-C/X-SAR around Japan, Proceedings of IGARSS '95, Firenze, Italy. DOI: 10.1109/IGARSS.1995.520244.

Matzler, C., Strozzi , T., Weise , T., Floricioiu, D.-M. and Rott, H., 1997. Microwave snowpack studies made in the Austrian Alps during the SIR-C/X-SAR experiment, International Journal of Remote Sensing, Vol. 18, Issue 12, 2505-2530. DOI: 10.1080/014311697217440 


\section{PREPRINT}

Mchone, J. F., et al, 2002. Space shuttle observations of terrestrial impact structures using SIR-C and X-SAR radars, Meteoritics \& Planetary Science, Vol. 37, Issue 3, 407-420. DOI: 10.1111/j.1945-5100.2002.tb00824.x.

Meadows, P., 1994. ERS-1 SAR analogue to digital convertor saturation, CEOS SAR Calibration Workshop, Ann Arbor Michigan.

Melsheimer, C., Alpers, W., Gade, M., 1998. Investigation of multifrequency/multipolarization radar signatures of rain cells over the ocean using SIR-C/X-SAR data, Journal of Geophysical Research: Oceans, vol. 103, issue C9, DOI: 10.1029/98JC00779.

Migliaccio, M., Gambardella, A. and Tranfaglia, M., 2007. SAR Polarimetry to Observe Oil Spills, IEEE Trans. on Geoscience and remote Sensing, Vol. 45 , Issue:2, 506 - 511. DOI: 10.1109/TGRS.2006.888097

Misra, T., S. S. Rana, V. H. Bora, N. M. Desai, C. V. N. Rao, Rajeevjyothi, 2006. SAR Payload of Radar Imaging Satellite (RISAT) of ISRO, Proceedings of EUSAR 2006, Dresden, Germany.

Mittermayer, J., S. Wollstadt, P. Prats, and R. Scheiber, 2014. The TerraSAR-X staring spotlight mode concept, IEEE Trans. Geosci. Remote Sens., Vol. 52, No. 6, 3695-3706.

Monaldo, F. and Beal, R. C., 1998. Comparison of SIR-C SAR wavenumber spectra with WAM model predictions, Journal of Geophysical Research: Oceans, vol. 103, issue C9, DOI: 10.1029/98JC01457.

Moore E., Freeman A., Hensley S., 2006. Spaceborne and Airborne Radar at Angkor: Introducing New Technology to the Ancient Site. In: Wiseman J., El-Baz F. (eds) Remote Sensing in Archaeology. Interdisciplinary Contributions to Archaeology. Springer, New York, NY, DOI: 10.1007/0-387-44455-6_8

Moore, R. K., Mogili, A., Fang, Y., Beh, B., and Ahamad, A., 1997. Rain measurement with SIR- C/X-SAR, Remote Sensing of Environment, Volume 59, Issue 2, 280-293, DOI: 10.1016/S0034-4257(96)00147-2.

Moreira, A., 1992. Real-Time Synthetic Aperture Radar (SAR) Processing with a New Subaperture Approach, IEEE Trans. on Geoscience and Remote Sensing, Vol. 30, No. 4, 714-722. DOI: $10.1109 / 36.158865$

Moreira, A., Krieger, G., Hajnsek, I., Papathanassiou, K., Younis, M., Lopez-Dekker, F., Huber, S., Villano, M., Pardini, M., Eineder, M., De Zan, F., and Parizzi, A., 2015. Tandem-L: A Highly Innovative Bistatic SAR Mission for Global Observation of Dynamic Processes on the Earth's Surface. IEEE Geoscience and Remote Sensing Magazine (GRSM), Vol. 3, No.2, $8-23$.

Moreira, J., et al, 1995. X-SAR Interferometry: First Results. IEEE Trans. on Geoscience and Remote Sensing, Vol. 33, No. 4, 950-956.

Mouginis-Mark, P. J., 1995. Preliminary observations of volcanoes with the SIR-C radar. IEEE Trans. on Geoscience and Remote Sensing, Vol. 33, No. 4, 934-941.

Nagai, T., Yamaguchi, Y., Yamada, H., 1997. Use of Multi-Polarimetric Enhanced Images in SIR-C/X-SAR Land-Cover Classification, IEICE TRANSACTIONS on Communications, Vol. E80-B, No.11, 1696-1702.

Narayanan, R. and Hirsave, P. P., 2001. Soil moisture estimation models using SIR-C SAR data: a case study in New Hampshire, USA, Remote Sensing of Environment, Vol. 75, Issue 3, 385-396 .DOI: 10.1016/S0034-4257(00)00181-4

Nomoko, Y., et al, 1991. Japanese Earth Resources Satellite-1 Synthetic Aperture Radar, Proceedings of the IEEE, Vol. 79, No. 6. 


\section{PREPRINT}

Öttl, H., 1997. The SIR-C/X-SAR Missions - Overview and some Results, Acta Astronautica. Vol. 41, No. 3, 155-163.

Paloscia, S., 2002. A summary of experimental results to assess the contribution of SAR for mapping vegetation biomass and soil moisture. Can. J. Remote Sens., 2 , 246 - 261, DOI: $10.5589 / \mathrm{m} 02-020$

Pierce, 1. E., et al, 1994. Knowledge-based classification of polarimetric SAR images, IEEE Trans. on Geoscience and remote Sensing, Vol. 32 , Issue 5, 1081 - 1086. DOI: $10.1109 / 36.312896$.

Pierce, 1. E., et al, 1998. Multitemporal Land-Cover Classification Using SIR-C/X-SAR Imagery, Remote Sensing of Environment Volume 64, Issue 1, 20-33 DOI: 10.1016/S00344257(97)00165-X

Ponte, S. and Vetrella, S., 1997. The SIR-C/X-SAR Italian experiments at Matera: Instrumentation and measurement results, Remote Sensing of Environment, Volume 59, Issue 2, 397-406, DOI: 10.1016/S0034-4257(96)00162-9.

Pope, K. O., Rejmankova, E., Paris, J. F., Woodruff, R., 1997. Detecting seasonal flooding cycles in marshes of the Yucatan Peninsula with SIR-C polarimetric radar imagery, Remote Sensing of Environment, Volume 59, Issue 2, 157-166, DOI: 10.1016/S00344257(96)00151-4.

Pope, K. O., Rejmankova, E. , and Paris, J.F., 2001. Spaceborne imaging radar-C (SIR-C) observations of groundwater discharge and wetlands associated with the Chicxulub impact crater, northwestern Yucatan Peninsula, Mexico. Geol. Soc. Am. Bull. , 3 , 403 - 416, DOI: 10.1130/0016-7606(2001)113<0403:SIRCSC>2.0.CO;2

Pultz, T. J., Crevier, Y., Brown, R.J. and Boisvert, J. 1997. Monitoring local environmental conditions with SIR-C/X-SAR, Remote Sensing of Environment, Volume 59, Issue 2, 248255, DOI: 10.1016/S0034-4257(96)00157-5.

Purdue, 2019. SNoOPI: Purdue CubeSat Project Selected for Flight by NASA.

Ramadan, T. M., Abdelsalam, M. G., and Stern, R. J., 2001. Mapping Gold-Bearing Massive Sulfide Deposits in the Neoproterozoic Allaqi Suture, Southeast Egypt with Landsat TM and SIR-C/X SAR Images, Photogrammetric Engineering \& Remote Sensing, Vol. 67, No. 4, 497., DOI: 0099-1112/01/6704-491\$3.00.

Raney, R. K. and Freeman, A., 2009. Hybrid-Polarity SAR Architecture, Proc. PolinSAR 2009, Frascati, Italy.

Ranson, K. J., Ulaby, F. T., and Pierce, L. E., 1995. Boreal forest ecosystem characterization with SIR-C/XSAR. IEEE Trans. on Geoscience and Remote Sensing, Vol. 33, No. 4, 867876.

Ranson, K. J. and Sun, G., 1997. An evaluation of AIRSAR and SIR-C/X-SAR images for mapping northern forest attributes in Maine, USA, Remote Sensing of Environment, Volume 59, Issue 2, 203-222, DOI: 10.1016/S0034-4257(96)00154-X.

Ranson, K. J., et al, 2001. Characterization of Forests in Western Sayani Mountains, Siberia from SIR-C SAR Data, Remote Sensing of Environment, Vol. 75, Issue 2, 188-200 .DOI: 10.1016/S0034-4257(00)00166-8

Reigber. A. and Moreira, A., 2000. First demonstration of air-borne SAR tomography using multibaseline L-band data, IEEE Trans. Geosci. Remote Sens., vol. 38, no. 5, 2142- 2152.

Rignot, E., William A. Salas, W. A., and Skole, D. L., 1997. Mapping deforestation and secondary growth in Rondonia, Brazil, using imaging radar and thematic mapper data, 


\section{PREPRINT}

Remote Sensing of Environment, Volume 59, Issue 2, 167-179, DOI: 10.1016/S00344257(96)00150-2.

Rizzoli, P., Martone, M., Gonzalez, C., Wecklich, C., Tridon, D. B., Bräutigam, B., . Bachmann, M., Schulze, D., Fritz, T., Huber, M., Wessel, B., Krieger, G., Zink, M, Moreira, A., 2017. Generation and performance assessment of the global TanDEM-X digital elevation model. ISPRS journal of photogrammetry and remote sensing, 132, 119-139.

Romeiser, R., et al, 2002. Study on Concepts for Radar Interferometry from Satellites for Ocean (and Land) Applications (KoRIOLiS), http://www.ifm.uni-

hamburg.de/ romeiser/koriolis.htm, University of Hamburg Technical Report (April 2002).

Rosen, P. A., S. Hensley, H. A. Zebker, F. H. Webb, and E. J. Fielding, 1996. Surface deformation and coherence measurements of Kilauea volcano, Hawaii, from SIR-C radar interferometry, J. Geophys. Res.-Planets, vol. 101, no. E10, 23109-23125.

Rosen, P., et al, Synthetic Aperture Radar Interferometry, 2000. Proc. IEEE, Vol. 88, No. 3, 333382.

Rosenqvist, A., Shimada, M., Chapman, B., Freeman, A., De Grandi, G.F., Saatchi, S. and Rauste, Y. 2000. The Global Rain Forest Mapping project - A review. International Journal of Remote Sensing, Vol. 21, No. 6\&7, 1375-1387.

Ruf, C. S., et al, 2018. A New Paradigm in Earth Environmental Monitoring with the CYGNSS Small Satellite Constellation, Nature Scientific Reports I (2018) 8:8782 I DOI:10.1038/s41598-018-2712.

Saatchi, S., Vianei Soares, J., Salas Alves, D., 1997. Mapping deforestation and land use in amazon rainforest by using SIR-C imagery, Remote Sensing of Environment, Volume 59, Issue 2, 191-202, DOI: 10.1016/S0034-4257(96)00153-8.

Saito, H., et al, 2018. Engineering-Model Results of Compact X-Band Synthetic Aperture Radar, 4S Symposium, Sorrento, Italy.

Sarabandi, K., L. Pierce, M.C. Dobson, F.T. Ulaby, J. Stiles, T.C. Chiu, R. De Roo, R. Hartikka, A. Zambetti, and A. Freeman, 1995. Polarimetric calibration of SIR-C using point and distributed targets, IEEE Trans. on Geoscience and Remote Sensing, vol. 33, no. 4, 858-866.

Schaber, G., McCauley, J. F. and Breed, C., 1997. The use of multifrequency and polarimetric SIR-C/X-SAR data in geologic studies of Bir Safsaf, Egypt, Remote Sensing of Environment, Vol. 59, Issue 2, 337-363. DOI: 10.1016/S0034-4257(96)00143-5

Schmullius, C. C., and Evans, D. L., 1997. Review article Synthetic aperture radar (SAR) frequency and polarization requirements for applications in ecology, geology, hydrology, and oceanography: A tabular status quo after SIR-C/X-SAR, International Journal of Remote Sensing, Vol. 18, Issue 13, 2713-2722. DOI: 10.1080/014311697217297

Séguin, G., 2005. A Canadian Constellation of C-Band SAR Satellites, Proceedings of the 56th IAC 2005, Fukuoda, Japan.

Shah, R., Garrison, P., and Freeman, A., 2018. Constellations of CubeSats to exploit signals-ofopportunity for Earth system science, Proceedings SPIE Optical Engineering + Applications, Vol. 10769, CubeSats and NanoSats for Remote Sensing II; 107690D, San Diego, CA.

Shi, J. C., and Dozier, J., 1995. Inferring Snow Wetness using C-Band Data from SIR-C's Polarimetric Synthetic Aperture Radar. IEEE Trans. on Geoscience and Remote Sensing, Vol. 33, No. 4, 905-914.

Shi, J. C., and Dozier, J., 1997. Mapping seasonal snow with SIR-C/X-SAR in mountainous areas, Remote Sensing of Environment, Volume 59, Issue 2, 294-307, DOI: 10.1016/S00344257(96)00146-0. 


\section{PREPRINT}

Shi, J. C. and Dozier, J., 2000. Estimation of snow water equivalence using SIR-C/X-SAR. I. Inferring snow density and subsurface properties, IEEE Trans. on Geoscience and remote Sensing, Vol. 38 , Issue 6, 2465 - 2474. DOI: 10.1109/36.885195

Shi, J. C. and Dozier, J., 2000. Estimation of snow water equivalence using SIR-C/X-SAR. II. Inferring snow depth and particle size, IEEE Trans. on Geoscience and remote Sensing, Vol. 38, Issue 6, 2475 - 2488. DOI: 10.1109/36.885196

Shimada, M., 2009. Advanced Land Observation Satellite (ALOS) and its follow-on satellite, ALOS-2, Proceedings of the 4th International PolInSAR 2009 Workshop, ESA/ESRIN, Frascati, Italy.

Shimada, M., et al, 2009. PALSAR Radiometric and Geometric Calibration, IEEE Transactions on Geoscience and Remote Sensing, Vol. 47, No. 12, Dec 2009

Siqueira, P., Hensley, S., Shaffer, S., Hess, L., McGarragh, G., Chapman, B., and Freeman, A., 2000. A Continental-Scale Mosaic of the Amazon Basin Using JERS-1 SAR, IEEE Trans. on Geoscience and Remote Sensing, Vol. 38, No. 6, 2638-2644.

Snoeij, P., et al, 2010. C-SAR Instrument Design for the Sentinel-1 Mission, IEEE Radar Conference 2010, Washington, DC.

Soares, J. V., Renno, C. D., Formaggio, A. R., Yanasse, C., and Frery, A. C., 1997 An investigation of the selection of texture features for crop discrimination using SAR imagery, Remote Sensing of Environment, Volume 59, Issue 2, 234-247, DOI: 10.1016/S00344257(96)00156-3.

Souyris, J. C., et al, 1995. Inversion of Landes Forest biomass using SIR-C/X-SAR data: experiment and theory, Proceedings of IGARSS '95, Firenze, Italy. DOI: 10.1109/IGARSS.1995.521183.

Spencer, M., Chan, S., Veilleux, L., and Wheeler, K., 2009. The Soil Moisture Active/Passive (SMAP) Mission Radar: a Novel Conically Scanning SAR, Proceedings of the 2009 IEEE Radar Conference, Pasadena, CA, USA.

Stern, R. J. and Abdelsalam, M. G., 1996. The Origin of the Great Bend of the Nile from SIRC/X-SAR Imagery, Science, Vol. 274, Issue 5293, pp. 1696-1698.

DOI:10.1126/science.274.5293.1696

Stofan, E. R., et al, 1995. Overview of Results of Spaceborne Imaging Radar-C, X-band Synthetic Aperture Radar (SIR-C/X-SAR). IEEE Trans. on Geoscience and Remote Sensing, Vol. 33, No. 4, 817-828.

Stuhr, F., Jordan, R. 1., and Werner, M., 1995. SIR-C/X-SAR: a multifaceted radar, International Proceedings International Radar Conference, Alexandria, VA. DOI: 10.1109/RADAR.1995.522519.

USGS, 2019. USGS EROS Data Center SIR-C Data Archive. https://www.usgs.gov/centers/eros/science/usgs-eros-archive-radar-spaceborne-imagingradar-c-band-sir-c?qt-science_center_objects=0\#qt-science_center_objects (accessed 22 March 2019)

van Zyl, J. J., 1989. Unsupervised classification of scattering behavior using radar polarimetry data, IEEE Trans. on Geoscience and Remote Sensing, Vol. 27, No. 1, 36-45.

Wang, J.R., Hsu, A. Shi, J.C. O'Neill, P.E. Engman, E.T., 1997. A comparison of soil moisture retrieval models using SIR-C measurements over the little Washita River watershed, Remote Sensing of Environment, Volume 59, Issue 2, 308-320, DOI: 10.1016/S00344257(96)00145-9. 
Weeks, R., Smith, M., Pak, K. and Gillespie, A., 1997. Inversions of SIR-C and AIRSAR data for the roughness of geological surfaces, Remote Sensing of Environment, Volume 59, Issue 2, 383-396, DOI: 10.1016/S0034-4257(96)00161-7.

Werninghaus, R., Balzer, W., Buckreuss, S., Mittermayer, J., Mühlbauer, P., Pitz, W., 2004. The TerraSAR-X Mission, Proceedings of EUSAR 2004, Ulm, Germany.

Yanasse, C. F., Sant'Anna, S. J. S, Frery, A. C., Renno, C., Soares, J. V. and Luckman, A. J., 1997. Exploratory study of the relationship between tropical forest regeneration stages and SIR-C L and C data, Remote Sensing of Environment, Volume 59, Issue 2, 180-190, DOI: 10.1016/S0034-4257(96)00149-6.

Yokota, Y. Okada, K. Iribe, M. Tsuji, A, Ando, Y. Kunii, 2013. Newly developed X-band SAR system onboard Japanese small satellite "ASNARO-2", Published in: Synthetic Aperture Radar (APSAR), 2013 Asia-Pacific Conference, 23-27 Sept. 2013, Tsukuba, Japan.

Zebker, H. A., Rosen, P., Hensley, S. and Mouginis-Mark, P.J., 1996. Analysis of active lava flows on Kilauea Volcano, Hawaii, using SIR-C radar correlation measurements. Geology, 6 , 495 - 498, DOI: 10.1130/0091-7613(1996)024<0495:AOALFO>2.3.CO;2

Zink, M. W., and Bamler, R., 1995. X-SAR Radiometric Calibration and Data Quality. IEEE Trans. on Geoscience and Remote Sensing, Vol. 33, No. 4, 840-847.

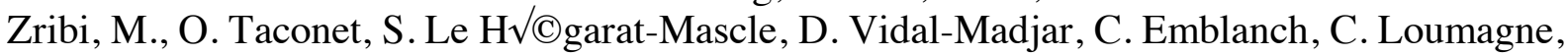
M. Normand, 1997. Backscattering behavior and simulation comparison over bare soils using SIR-C/X-SAR and ERASME 1994 data over Orgeval, Remote Sensing of Environment, Volume 59, Issue 2, 256-266, DOI: 10.1016/S0034-4257(96)00158-7.

Zink, M. et al., 2014. TanDEM-X: the new global DEM takes shape. IEEE Geoscience \& Remote Sensing Magazine 2 (2), 8-23. 